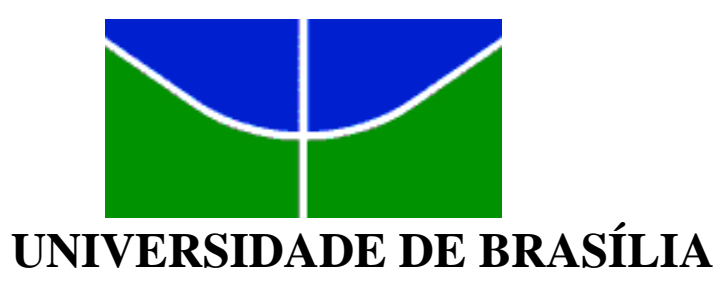

FACULDADE DE AGRONOMIA E MEDICINA VETERINÁRIA

\title{
DOENÇAS DA CAVIDADE NASAL EM PEQUENOS RUMINANTES NO DISTRITO FEDERAL E ENTORNO
}

VANESSA DA SILVA MUSTAFA

TESE DE DOUTORADO EM CIÊNCIAS ANIMAIS

BRASÍLIA-DF

DEZEMBRO DE 2014 


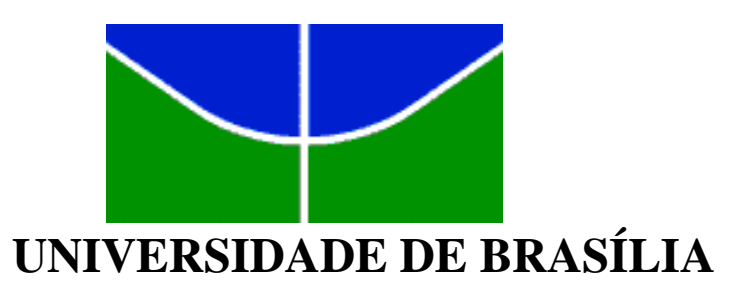

FACULDADE DE AGRONOMIA E MEDICINA VETERINÁRIA

\section{DOENÇAS DA CAVIDADE NASAL EM PEQUENOS RUMINANTES NO DISTRITO FEDERAL E ENTORNO}

VANESSA DA SILVA MUSTAFA

ORIENTADOR: MÁRCIO BOTELHO DE CASTRO

TESE DE DOUTORADO EM CIÊNCIAS ANIMAIS PUBLICAÇÃO: 116D/2014

BRASÍLIA-DF

DEZEMBRO DE 2014 
Ficha catalográfica elaborada pela Biblioteca Central da Universidade de Brasília. Acervo 1019237.

Mustafa, Vanessa da Silva.

M991d Doenças da cavidade nasal em pequenos ruminantes no Distrito Federal e Entorno / Vanessa da Silva Mustafa. - 2014.

v, $54 \mathrm{f.}:$ il. ; $30 \mathrm{~cm}$.

Tese (doutorado) - Universidade de Brasília, Faculdade de Agronomia e Medicina Veterinária, Programa de Pós-Graduação em Ciências Animais, 2014.

Orientação: Márcio Botelho de Castro.

Inclui bibliografia.

1. Ruminante - Doenças - Distrito Federal (Brasil).

2. Rinite. 3. Parasitologia veterinária. I. Castro, Márcio Botelho de. II. Título.

CDU 636.2:619 


\title{
DOENÇAS DA CAVIDADE NASAL EM PEQUENOS RUMINANTES \\ NO DISTRITO FEDERAL E ENTORNO
}

\author{
VANESSA DA SILVA MUSTAFA
}

TESE DE DOUTORADO SUBMETIDA AO PROGRAMA DE PÓS-GRADUAÇÃO EM CIÊNCIAS ANIMAIS, COMO PARTE DOS REQUISITOS NECESSÁRIOS À OBTENÇÃO DO GRAU DE DOUTOR EM CIÊNCIAS ANIMAIS.

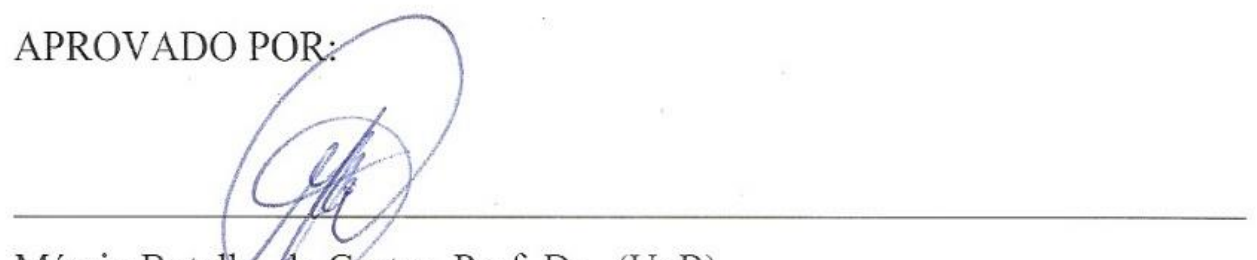

Márcio Botelho de Castro, Prof. Dr., (UnB)

\section{Giome \& Aaledo}

Giane Regina Paludo, Profa. Dra., (UnB)

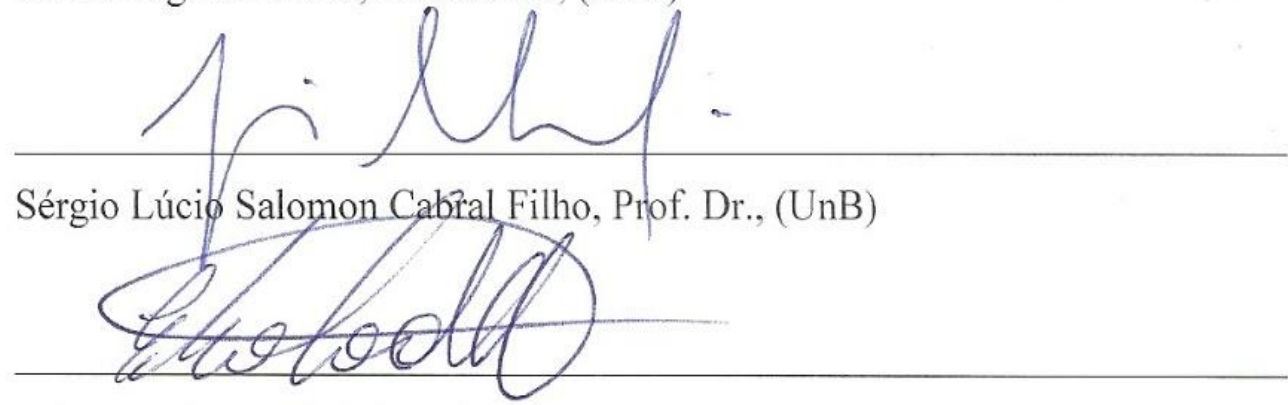

Edson Moleta Colodel, Prof. Dr., (UFMT)

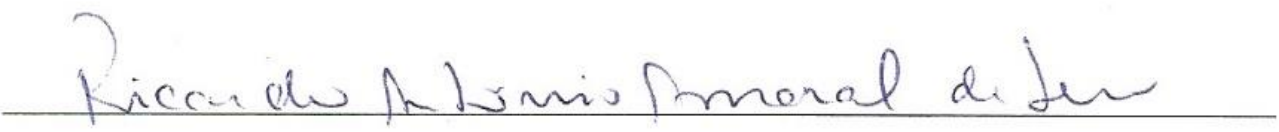

Ricardo Antonio Amaral de Lemos, Prof. Dr., (UFMS) 


\section{ÍNDICE}

Capítulos / Subcapítulos

Página

RESUMO

$\mathrm{V}$

ABSTRACT

vi

CAPÍTULO I

1

1- INTRODUÇÃO

2

1.1- PROBLEMÁTICA E RELEVÂNCIA

4

1.2- OBJETIVOS

5

2- REVISÃO DE LITERATURA

CAPÍTULO II

1- RESUMO

2- ABSTRACT

18

3- INTRODUÇÃO

19

4- MATERIAL E MÉTODOS 21

5- RESULTADOS

5.1- Pitiose rinofacial 23

5.2- Conidiobolomicose 25

5.3- Oestrose 31

6- DISCUSSÃO 36

7- CONCLUSÕES 46

8- REFERÊNCIAS BIBLIOGRÁFICAS 48 


\section{RESUMO}

\section{DOENÇAS DA CAVIDADE NASAL EM PEQUENOS RUMINANTES NO DISTRITO}

FEDERAL E ENTORNO: Vanessa da Silva Mustafa, doutaranda em Ciências Animais pela Universidade de Brasília; Márcio Botelho de Castro, professor doutor da Universidade de Brasília, Brasília/DF. A ovinocultura e caprinocultura apresenta intenso crescimento na região central do Brasil. A baixa condição sanitária dos rebanhos brasileiros e o transporte desorganizado de animais entre as regiões favorece que doenças se disseminem pelo território nacional. As rinites parasitárias, micótica e oomicóticas são doenças de baixa prevalência mas que provocam prejuízos significativos. Foi realizado levantamento dos laudos do Laboratório de Patologia Veterinária da Universidade de Brasília (LPV-UnB) nos anos de 2003 a 2014 para verificar a ocorrência da oestrose, pitiose rinofacial e conidiobolomicose em ovinos e caprinos. Foi observada uma prevalência de oestrose em 4,08\% dos pequenos ruminantes, sendo $86,36 \%$ ovinos e 13,64\% de caprinos. A maioria dos casos ocorreu na época das secas. Os animais apresentavam secreção nasal, dispneia e apatia. Apesar de não ser correlacionada com a morte dos animais, essa parasitose causa diminuição marcante na produção animal. Quatro surtos de rinite micótica ou oomicótica foram observados no Distrito Federal e Goiás. O agente etiológico foi identificado por reação da polimerase em cadeia ou por imuno-histoquímica, como Pythium insidiosum em dois surtos no DF e Conidiobolus lamprauges nos demais. A pitiose rinofacial apresentou morbidade de 7,27\% com letalidade de $75 \%$. Nos surtos de conidiobolomicose no estado de Goiás foi observada morbidade de 4,28\% a 7,39\% com letalidade de $100 \%$. Os sinais mais comuns são dispneia, secreção nasal e apatia. Durante a necropsia observou-se tecido de granulação necrótico na cavidade nasal, localizada em região rinofacial, nos casos de pitiose, ou na região rinofaríngea, nos casos de conidiobolomicose. A importância dessas rinites vem aumentando na região, devido aumento no rebanho ovino e falta de conhecimento a prevenção. O conhecimento das rinites causadas por diferentes agentes permite o diagnóstico diferencial e possibilita a recomendação medidas de controle e profilaxia. É a primeira vez que essas doenças são descritas nesses estados.

Termos de indexação: Rinite parasitária, rinite micótica, rinite fúngica, Conidiobolus lamprauges, Pythium insidiosum, Oestrus ovis. 


\begin{abstract}
DISEASES OF NASAL CAVITY IN SMALL RUMINANT IN THE DISTRITO FEDERAL AND SURROUNDING: Vanessa da Silva Mustafa, doutaranda em Ciências Animais pela Universidade de Brasília; Márcio Botelho de Castro, professor doutor da Universidade de Brasília, Brasília/DF. The goat and sheep industry show strong growth in central Brazil. The low health status of Brazilian herds and disorganized transport of animals between regions that favors disease from spreading throughout the Brazil. As rinites parasitárias, micótica e oomicóticas são doenças de baixa prevalência mas que provocam prejuízos significativos. A retrospective data collection of necropsy and histopathology cases performed at the Veterinary Pathology Laboratory of University of Brasília (LPV-UnB) from 2003 to 2012 was done to verify the occurrence of oestrose, pythiosis rhinofacial and conidiobolomycosis in sheep and goats. It was observed a $4.08 \%$ prevalence of parasitized animals, of which $86.36 \%$ were ovine and $13.64 \%$ were caprine. The majority of the cases occurred during the dry season. The animals presented lethargy, nasal discharge, diarrhea and dyspnea. Although oestrosis is not an important cause of death in sheep, the economic losses related to nasal cavity irritation and decrease in food intake can generate even more significant losses than what is expected. Four outbreaks of mycotic or oomycotic rhinitis were observed in Distrito Federal (DF) and Goiás. The etiologic agent was identified by polymerase chain reaction or by immunohistochemistry as Pythium insidiosum in two outbreaks in DF and Conidiobolus lamprauges in the other two. The rhinofacial pythiosis presented $7.27 \%$ of morbidity and $75 \%$ of lethality in DF outbreaks. In the state of Goiás outbreaks, it was observed morbidity of $4.28 \%$ to $7.39 \%$ with $100 \%$ lethality. The affected animals presented dyspnea, purulent or serosanguinous nasal discharge and lethargy. The main lesion consisted of severe and extensive necrosis in the nasal cavity, located on rhinofacial region in pythiosis cases, or on rhinopharyngeal region in sheep with conidiobolomycosis. The importance of these rhinitis is increasing in the region due to increased herd sheep and lack of knowledge on prevention. Knowledge of rhinitis caused by different agents allows the differential diagnosis and possible recommendation for control and prevention measures. It is the first time that these diseases are described in these states.
\end{abstract}

Indexing terms: Rhinitis parasitic, mycotic rhinitis, fungal rhinitis, Conidiobolus lamprauges, Pythium insidiosum, Oestrus ovis. 


\section{CAPÍTULO I}




\section{1- INTRODUÇÃO}

O Centro-Oeste é a região que apresenta o maior rebanho pecuário no Brasil e vem apresentando crescimento considerável na produção de pequenos ruminantes na última década. Nessa região houve acentuado crescimento nesse período, e tornou-se a quarta maior produtora de leite caprino no Brasil (IBGE, 2009, Lopes et. al. 2010). No estado de Goiás e no Distrito Federal a ovinocultura também apresentou forte desenvolvimento (ANUALPEC, 2007; IBGE, 2009).

$\mathrm{O}$ incremento da atividade pecuária de pequenos ruminantes trouxe consigo novas doenças ainda desconhecidas na região e que podem emergir como importantes causas de prejuízo para a atividade. As doenças emergentes podem ser definidas como as infecções que surgiram recentemente em uma população ou que já existiam, e têm aumentado rapidamente em incidência e alcance geográfico. Podem ocorrer devido ao real surgimento ou identificação de novas doenças ou devido à mudança no comportamento epidemiológico de enfermidades previamente conhecidas (Luna, 2002, Grisotti, 2010).

O crescimento desorganizado dos rebanhos caprinos e ovinos, a importação de animais de outros países e a transferência de animais entre as regiões, propicia a introdução de doenças exóticas e a disseminação de doenças anteriormente restritas a uma determinada região (Pinheiro et. al. 2000, Guimarães, 2006).

A baixa condição sanitária dos animais é um entrave para a expansão das criações (Pinheiro et. al. 2000). A falta de conhecimento sobre manejo sanitário e nutricional aumenta o risco de ocorrência de doenças, tanto em sistemas tecnificados quanto em sistemas tradicionais (Pinheiro et. al. 2000, Gouveia, 2003). Compreender o perfil sanitário dos rebanhos e os fatores que influenciam na baixa produtividade é essencial para estabelecer metas que permitam soluções práticas visando maior lucratividade, maior expansão e menores perdas na caprinovinocultura (Alencar et al. 2010; Rissi et. al. 2010).

No Distrito Federal e Entorno, doenças como parasitismo intestinal, intoxicação por braquiária, distocia, desnutrição, pneumonia e toxemia da prenhez são relatadas com frequência em pequenos ruminantes sendo importantes causas de perdas econômicas nessa região. Estima-se que os problemas associados ao sistema intensivo de criação devam aumentar devido ao crescimento desse tipo de manejo na região do Brasil Central (Borges et al. 2007).

Apesar de ainda pouco conhecidas, as rinites em ruminantes causam prejuízos econômicos associados a morte de animais ou perda na produtividade (Portela et. al. 2010). 
Diversos agentes podem estar envolvidos na etiologia da enfermidade, mas entre esses, fungos e parasitas vem surgindo na região como causas importantes, causando prejuízo nos rebanhos.

A larva da mosca Oestrus ovis vem aumentando a sua importância nos rebanhos e seu efeito patogênico é frequentemente subestimado, apesar da sua alta prevalência em ovinos e caprinos e seu moderado potencial zoonótico (Pampiglione et. al. 1997). No entanto, perdas significativas são associadas a esse parasita, chegando a $22 \%$ do ganho de peso, $10 \%$ da produção de leite e $16 \%$ da produção de lã (Silva et. al. 2001). As descrições de oestrose em pequenos ruminantes no Brasil Central são escassas e pouco se conhece sobre sua incidência atual, distribuição e epidemiologia nessa região (Borges et. al. 2007; Cansi et. al 2011).

A conidiobolomicose e a pitiose rinofacial também vem surgindo na região Centro-Oeste e são as duas principais causas de rinites em ruminantes no estado da Paraíba (Portela et. al. 2010). As rinites granulomatosas micóticas ou oomicóticas apresentam alta letalidade, com pouca resposta ao tratamento. Apesar de descritas em vários estados brasileiros ainda não havia sido observada no Distrito Federal e Entorno (Tabosa et. al. 2004, Silva et. al. 2007a, Boabaid et. al. 2008, Riet-Correa et. al. 2008, Pedroso et. al. 2009, Furlan et. al. 2010, Portela et. al. 2010, Aguiar et. al. 2014, Galiza et. al. 2014).

As condições climáticas do Distrito Federal e Entorno, com temperaturas moderadas e constantes durante todo o ano e regime de chuvas bem definido, parecem favorecer a manutenção dos agentes no meio ambiente e predispor a ocorrência de rinites micóticas e oomicóticas. Não se conhece até o momento os aspectos epidemiológicos dessas doenças na região, apesar de haver relato de casos sem identificação do agente (Porto et. al. 2008).

O presente trabalho descreve as características clínico-epidemiológicas e anatomopatológicas da oestrose, pitiose rinofacial e conidiobolomicose observadas em pequenos ruminantes no Distrito Federal e Entorno. 


\section{1- Problemática e Relevância}

A ovinocultura e a caprinocultura estão em franca expansão em todas regiões do Brasil. O aumento no consumo de carne, leite e seus derivados desses animais abre um mercado consumidor amplo e que precisa ser atendido. Porém as condições sanitárias dos rebanhos brasileiros geram um enorme entrave para que o crescimento dessa criação seja exponencial como o crescimento da demanda do mercado.

A falta de conhecimento sobre a condição sanitária dos rebanhos, principalmente das doenças emergentes, dificulta o planejamento sanitário e nutricional adequados para cada região, permitindo a disseminação de diversas doenças e acarretando prejuízos econômicos significativos.

A oestrose é uma miíase nasal, que ocorre no Brasil desde o início do século XX, mas que até hoje não teve sua ocorrência controlada, sendo distribuída em todo Brasil. Apesar dessa doença raramente acarretar a morte do animal, ela gera diminuição na produção e pode predispor a ocorrência de doenças mais graves que culminem com a morte do animal. Sua caracterização epidemiológica na região do Distrito Federal e entorno ainda não é conhecida.

As zigomicoses são doenças granulomatosas raras que acometem homens e animais, causadas por fungos, com evolução grave e potencialmente letal. A ocorrência dessas doenças é maior em locais de clima quente e úmido, clima característico do Distrito Federal e entorno durante grande parte do ano. Em pequenos ruminantes as zigomicoses são causadas por um fungo da espécie Conidiobolus spp. que colonizam principalmente a cavidade nasal, causando rinite com formação de granuloma principalmente na região nasofaríngea. $\mathrm{O}$ animal apresenta dificuldade respiratória acentuada, secreção nasal, apatia e anorexia. $\mathrm{O}$ tratamento não apresenta boa eficácia se não for iniciado precocemente e a doença tende a culminar com a morte do animal.

A pitiose é uma doença granulomatosa que acomete animais e humanos, com maior ocorrência em áreas tropicais, subtropicais ou temperadas. O Pythium insidiosum é um pseudofungo pertencente a classe Oomycetes. Pode causar lesão em pele, cavidade nasal e pulmão. A apresentação clínica e aspecto macroscópico da rinite é semelhante ao observado na conidiobolomicose, porém com maior acometimento da região rinofacial, a diferenciação deve ser feita através de exames laboratoriais. O tratamento é ineficaz e quando acomete pulmão e cavidade nasal é geralmente fatal. 
Apesar da baixa incidência dessas doenças, sua ocorrência, epidemiologia, achados clínicos, anatomopatológicos e histopatológicos mais comuns não são conhecidos no Distrito Federal e entorno.

O conhecimento sobre essas enfermidades auxiliará o médico veterinário na conclusão do diagnóstico clínico e instituição da terapia adequada, além de permitir a elaboração de planos estratégicos e medidas preventivas que minimizem a ocorrência dessas rinites e a perda causada por elas na caprinocultura e ovinocultura.

\section{2- Objetivos}

O presente estudo tem por finalidade caracterizar os aspectos clínicos, epidemiológicos e anatomopatológicos da oestrose e das zigomicoses e pitiose em pequenos ruminantes no Distrito Federal e estado de Goiás. 


\section{2- REVISÃO DE LITERATURA}

\subsection{Conidiobolomicose e Pitiose}

Os fungos são micro-organismos eucariontes, uni ou pluricelulares e heterotróficos pertencentes ao Reino Fungi (Meireles \& Nascente 2009). Estima-se que aproximadamente 800.000 espécies de fungos tenham sido descritas, dentre essas, cerca de 400 espécies são patogênicas para humanos e animais (Quinn et. al. 2011). Conidiobolomicose (zigomicose ou murcomicose) é uma doença fúngica granulomatosa rara que afeta homens e animais (Silva et. al. 2007a) e várias espécies de artrópodes e aranhas (Moraes et. al. 1997). Esse fungo é saprófita e tem predileção pelo trato respiratório, mas pode acometer outras regiões do corpo (Carrigan et. al. 1992, Moraes et. al., 1997). Conidiobolus coronatus, C. lamprauges e $C$. incongruus já foram identificados como causa de enfermidade em animais (Carrigan et al. 1992, Morris et al. 2001, Silva et al. 2007ab, Furlan et. al. 2010, Portela et. al. 2010). Apesar de possuir distribuição mundial, sua frequência é baixa, refletindo-se no pouco conhecimento desta zoonose (Carrigan, 1992, Santurio et. al. 1998, Morris et. al. 2001).

Os oomicetos são micro-organismos eucariontes semelhantes aos fungos nas características morfológicas e de crescimento, porém, filogeneticamente diferem dos fungos e pertencem ao Reino Straminipila (Mendoza \& Newton 2005). Pythium insidiosum é o principal representante dessa classe de micro-organismos sendo responsável por infecções graves em humanos e em diferentes espécies animais (Mendoza et al. 1993, Mendoza et al. 1996, Galiza et. al. 2014). Dentre as doenças micóticas e oomicóticas do Sul do país a pitiose é a com maior prevalência, acometendo com maior frequência os equinos, animais de companhia e bovinos (Galiza et. al. 2014).

Conidiobolomicose e pitiose ocorrem em regiões úmidas de clima tropical, subtropical e temperado (Carrigan et. al. 1992, Mendoza et. al. 1996). Esses agentes se multiplicam em plantas aquáticas e se instalam no hospedeiro ou por inalação de esporos de Conidiobolus spp., por penetração dos zoósporos do P. insidiosum no folículo piloso íntegro, ou se implantam nos tecidos por lesões traumáticas causadas por restos de vegetais ou insetos contendo o agente (Miller, 1982, Carrigan et. al. 1992, Santurio et. al. 1998, Moraes et. al., 1997). 
O gênero Conidiobolus spp. é frequentemente associado com rinite granulomatosa crônica no homem e nos animais (Tadano et. al 2005, Silva et. al. 2007a, Boabaid et. al. 2008, Riet-Correa et. al. 2008, Aguiar et. al. 2014, Souza et. al 2014, Li et. al. 2014). Podendo inclusive acometer pulmão, cérebro e trato gastrointestinal (Boabaid et. al. 2008, Pedroso et. al 2009, Portela et. al. 2010, Câmara et. al. 2011, Aguiar et. al. 2014, Joulali et. al. 2014, Li et. al 2014, Showkat et. al. 2014). Pitiose é associada principalmente ao quadro de dermatite granulomatosa em animais e em humanos, sendo considerada um doença emergente (Leal et. al. 2001b, Headley \& Junior 2004, Tabosa et. al. 2004, Santurio et. al. 2006, Gabriel et. al. 2008, Vicarivento et. al. 2008, Galiza et. al. 2014). O oomiceto pode acometer também trato gastrointestinal, pulmão e cavidade nasal em equinos, caninos, felinos e ovinos (Leal et. al. 2001b, Santurio et. al. 2006, Riet-Correa et. al. 2008, Santurio et. al. 2008, Galiza et. al. 2014). Dentre as doenças micóticas e oomicóticas a pitiose é a de maior prevalência, afetando principalmente os equinos, seguidos pelos caninos e bovinos. A zigomicose é a principal micose diagnosticada em ruminantes, afetando principalmente o trato digestório (Galiza et. al. 2014a).

A pitiose em ovinos foi descrita pela primeira vez no Brasil em 2004 (Tabosa et. al. 2004). Foram observados dois surtos no estado da Paraíba, onde a manifestação clínica consistia de dermatite granulomatosa semelhante ao quadro observado comumente em equinos e raramente em bovinos (Leal et. al. 2001a, Sallis et. al. 2003, Headley et. al 2004, Tabosa et. al 2004, Gabriel et. al. 2008, Galiza et. al. 2014). Durante a necropsia desses ovinos foi observada lesão granulomatosa no pulmão além das lesões dérmicas (Tabosa et. al. 2004).

Atualmente, a pitiose em ovinos apresenta semelhanças com a conidiobolomicose, causando lesão principalmente na cavidade nasal (Riet-Correa et al. 2008, Santurio et. al. 2008, Portela et. al. 2010, Carrera et. al. 2013, Aguiar et. al. 2014). O hábito de pastejo baixo dos ovinos pode favorecer a contaminação através da inalação dos esporos (Silva et al. 2007b). As rinites dos ruminantes são um grupo heterogêneo de doenças que causam sinais semelhantes. O conhecimento das rinites causadas por diferentes agentes e de outras enfermidades não inflamatórias, como as neoplasias, e o seu diagnóstico diferencial é importante para que possam ser recomendadas medidas de controle e profilaxia (Portela et. al. 2010).

Conidiobolomicose e pitiose rinofacial são descritas em ovinos em estados da região Sul, Nordeste e Centro-oeste do Brasil, apesar da baixa morbidade a letalidade é alta, sendo próxima a $100 \%$ na maioria dos surtos. Os surtos ocorrem geralmente no período das chuvas ou logo após o seu término, sempre em propriedades onde há áreas alagadas com matéria 
vegetal ao redor, onde o animal se alimenta ou bebe água (Silva et. al. 2007b, Boabaid et. al. 2008, Riet-Correa et. al. 2008, Santurio et. al. 2008, Pedroso et. al. 2009, Furlan et. al. 2010, Portela et. al. 2010, Silva et. al. 2010, Câmara et. al. 2011, Mendonça et. al. 2012, Carrera et. al. 2013, Aguiar et. al. 2014). Podem ocorrer surtos no período da seca em propriedades onde as áreas permaneçam alagadas durante esse período e a matéria orgânica seja mantida próxima a essas áreas (Riet-Correa et. al. 2008, Aguiar et. al. 2014). Evitar o acesso dos animais a essas áreas alagáveis ou remover a matéria orgânica que circunda essas áreas é uma forma de diminuir a infecção dos animais (Tabosa et. al. 2004, Aguiar et. al. 2014).

A alta letalidade das doenças pode estar associada a ineficácia do tratamento e diagnóstico tardio ou errôneo. Na conidiobolomicose a eutanásia é indicada pois o tratamento não é eficaz (Portela et. al. 2010). O início tardio pode ser um dos fatores que influencia nessa ineficácia do tratamento, o diagnóstico precoce é importante para se iniciar a terapia apropriada o quanto antes (Herrera et. al. 2009, Portela et. al. 2010). Por causar uma lesão não dolorosa, a observação dos sinais clínicos ocorre quando a cavidade já está comprometida significativamente, dificultando a ação do medicamento e a cura do animal (Silva et. al. 2007b, Riet-Correa et. al. 2008, Portela et. al 2010). A cura espontânea é descrita em bovinos com pitiose cutânea (Gabriel et. al. 2008).

Infecções causadas por fungos e oomicetos muitas vezes não apresentam alterações clínicas características que permitam um diagnóstico presuntivo (Kaufman 1992, Jensen et al. 1996), Clinicamente observa-se dificuldade respiratória, respiração ruidosa, secreção nasal purulenta ou sanguinolenta, apatia e emagrecimento (Silva et. al. 2007b, Boabaid et. al. 2008, Riet-Correa et. al. 2008, Pedroso et. al. 2009, Furlan et. al. 2010, Portela et. al. 2010). Nos casos de conidiobolomicose há exoftalmia, na pitiose rinofacial geralmente não se observa exoftalmia e nota-se aumento de volume rostral na cavidade nasal (Riet-Correa et. al. 2008, Santurio et. al. 2008, Portela et. al. 2010, Carrera et. al. 2013).

A evolução clínica observada nos surtos de rinite micótica e oomicótica no Brasil é extremamente variável, são relatados cursos clínicos de 1 a 180 dias relacionados a Conidiobolus spp., e evolução clínica de 14 a 50 dias em casos de pitiose rinofacial em ovinos (Riet-Correa et. al. 2008, Santurio et. al. 2008, Portela et. al. 2010). A evolução clínica pode ser extremamente variável em função da extensão e gravidade da lesão e agente etiológico envolvido. Na forma rinofaríngea a evolução clínica tende a ser mais rápida. No entanto a cronicidade observada na análise histopatológica sugere que é necessário um tempo maior do que o descrito para o estabelecimento da lesão na cavidade nasal (Riet-Correa et. al. 2008). A 
tentativa de tratamento e a imunidade do animal podem interferir na evolução clínica (Portela et. al 2010).

A pitiose em equinos também apresenta curso variável, sendo descrita evolução de dias a vários meses, alguns animais podem desenvolver uma forma atípica com curso clínico superior há um ano. Acredita-se que nessa espécie o curso clínico esteja associada a eficiência do sistema imune, mesmo que o animal não consiga eliminar o agente é possível isolar a área afetada evitando o quadro de evolução progressiva, coma e morte (Leal et. al. 2001b, Sallis et. al. 2003).

Na necropsia a principal alteração caracteriza-se pela proliferação de uma massa na cavidade nasal, friável, de coloração amarronzada, amarelada ou avermelhada, e com áreas necróticas. Na conidiobolomicose há um comprometimento das conchas etmoidais, septo nasal, coanas, meatos nasais, com infiltração de placa cribriforme do osso etmoide, bulbo olfatório, córtex frontal do cérebro e órbita ocular causando exoftalmia. Também podem ser observadas lesões granulomatosas em linfonodos regionais, pulmão, trato gastrointestinal e rim (Silva et. al. 2007a, Boabaid et. al. 2008, Riet-Correa et. al. 2008, Santurio et. al. 2008, Pedroso et. al. 2009, Furlan et. al. 2010, Portela et. al. 2010, Carrera et. al. 2013). Na pitiose o tecido granulomatoso se prolifera da porção rostral até região média da cavidade nasal, podendo acometer palato duro e septo nasal, com áreas de osteólise e fistulas oronasais. Pode ocorrer comprometimento de linfonodos regionais e pulmão (Riet-Correa et. al. 2008, Santurio et. al. 2008, Portela et. al. 2010, Carrera et. al. 2013, Aguiar et. al. 2014). Para o diagnóstico diferencial entre ambas, além da localização da lesão é importante a observação histológica dos dois agentes (Portela et. al. 2010).

Microscopicamente, ambas as lesões consistem em granulomas multifocais, com centro necrótico, contendo hifas raramente septadas e com ramificações laterais, sendo rodeadas por reação de Splendore-Hoeppli (Riet-Correa et. al. 2008). As hifas do Conidiobolus spp. são mais largas, com paredes finas e com contornos não paralelos, enquanto as hifas de Pythium insidiosum são mais delgadas, com paredes mais espessas e menor intensidade de reação de Splendore-Hoeppli ao redor (Leal et. al 2001a, Santurio et. al. 2006, Boabaid. et. al. 2008, Portela et. al 2010). Estas doenças apresentam características lesionais macroscópicas e microscópicas muito similares, dificultando sua diferenciação. Sendo necessário o cultivo ou a realização de exames mais sensíveis para determinar o agente (Reis Jr \& Nogueira 2002, Gabriel et. al. 2008, Silveira et. al. 2013, Galiza et. al. 2014). Em equinos, a caracterização clínica das feridas cutâneas granulomatosas, associada ao resultado histopatológico sugestivo 
para pitiose cutânea equina, constituem métodos de diagnóstico confiáveis, os quais podem ser confirmados pela técnica de imuno-histoquímica (Dória et. al. 2014).

O tratamento na conidiobolomicose em animais é ineficiente e a eutanásia é recomendada (Portela et. al. 2010, Aguiar et. al. 2014). Na pitiose o tratamento é difícil e vários tratamentos têm sido instituídos utilizando métodos químicos (antifúngicos), cirúrgicos e imunoterápicos, sendo seu sucesso influenciado pelo tamanho da lesão, local e duração das lesões, assim como a idade e o estado nutricional do animal (Headley \& Junior 2004, Biava et. al. 2007, Silva et. al. 2007b, Boabaid et. al. 2008).

Outro fator importante que dificulta o tratamento da pitiose é a composição de sua parede celular. Os fungos verdadeiros possuem quitina em sua parede, enquanto o Pythium spp. contém celulose e b-glucanos. A membrana plasmática não contém esteroides que é o componente-alvo de ação da maioria das drogas antifúngicas. Devido a essas características, as drogas antifúngicas tradicionais são ineficientes contra o P. insidiosum (Foil, 1996).

Em humanos o tratamento prolongado com antifúngicos, iodeto de potássio, anfotericina B, associado a excisão cirúrgica e câmaras hiperbáricas mostra boa eficiência, principalmente se o diagnóstico for precoce (Souza et. al. 2014). Um ovino tratado com iodeto de potássio mostrou regressão completa da lesão granulomatosa cutânea em 15 dias (Tabosa et. al. 2004). O uso de antifúngico, antibióticos, vitaminas e terapia de suporte se mostrou eficaz, podendo ser associado a imunoterapia (Portela et. al 2010, Carrera et. al 2013).

A imunoterapia tem sido outra ferramenta no tratamento da pitiose, mostrando boa eficácia especialmente em equinos infectados, nesses animais ela altera o padrão da resposta inflamatória de eosinofílica para mononuclear (Frey Jr et. al. 2007, Gabriel et. al. 2008, Carrera et. al. 2013). Para o tratamento de pitiose em ovinos o uso de imunoterápicos equinos mostrou eficiência de 16,7\% (Carrera et. al 2013).

Em bovinos é descrita cura espontânea em animais com pitiose cutânea, acreditase que isso não ocorra em ovinos pois, os animais não tratados tiveram evolução para morte (Tabosa et. al. 2004, Gabriel et. al. 2008, Riet-Correa et. al. 2008, Santurio et. al. 2008, Carrera et. al 2013). Enquanto equinos desenvolvem resposta tipicamente eosinofílica os bovinos apresentam inflamação mononuclear granulomatosa, que aparentemente é mais eficaz no combate as hifas, favorecendo a auto cura (Gabriel et. al. 2008).

Por ser uma doença de alta letalidade e com tratamento pouco eficaz, é importante conhecer a epidemiologia da doença para estabelecer medidas de controle que diminuam o prejuízo econômico causado por ela e facilitem o diagnóstico pelo veterinário, 
possibilitando o início do tratamento nos casos de pitiose rinofacial o quanto antes aumentando sua eficácia.

\subsection{Oestrose}

Oestrus ovis é um parasita economicamente importante da cavidade nasal e dos seios adjacentes em ovinos e caprinos em todo o mundo. Afeta negativamente a saúde de pequenos ruminantes, causando irritação nas vias respiratórias, infecções bacterianas secundárias e perdas econômicas devido à redução na produção de carne e leite (Caracappa et. al. 2000, Dorchies et. al 2000, Murguia et. al 2000, Caracappa et. al. 2000, Tabouret et. al. 2001, Alcaide et al. 2003, Arslan et. al 2009, Shoorijeh et al. 2009).

O efeito patogênico do Oestrus ovis é frequentemente subestimado, apesar da sua alta prevalência em ovinos e caprinos e seu moderado potencial zoonótico (Pampiglione et. al. 1997). Durante o desenvolvimento larval na cavidade naso-sinusal ocorre perturbação nos animais que pode ter consequências graves para a produção pecuária causando perdas na produção de carne, lã e leite (Caracappa et. al. 2000, Alcaide et. al. 2005).

Oestrose é endêmica em países de clima quente e seco, demonstrando alta prevalência em todo o mundo, com índices acima de 30\% no México (Martínez et. al. 1992), Espanha, Índia, Nigéria e Grécia (Jagannath et. al 1989, Papadopoulos et. al. 1997, Biu \& Nwosu, 1999, Alcaide et. al. 2005, Suárez et. al. 2005).

A oestrose foi descrita pela primeira vez no Brasil em 1916, no Rio de Janeiro. Onde foi observada sintomatologia clínica em dois carneiros importados da Europa, presença de larvas em animais de matadouro e a mosca adulta foi apanhada na região. Esse parasita foi introduzido no país juntamente com animais importados da Europa, onde a ocorrência dessa doença já era descrita (Lutz, 1917).

Atualmente, a oestrose já foi descrita na região sul e sudeste, nos estados de Santa Catarina, Rio Grande do Sul e São Paulo (Ribeiro et. al. 1990, Ramos et. al. 2006, Rissi et. al. 2010, Silva et. al. 2012). Em animais naturalmente infectados a prevalência observada foi de 0,3\% (Rissi et. al. 2010). No Centro-Oeste do Brasil, larvas de Oestrus ovis foram identificadas na cavidade nasal de caprinos e ovinos necropsiados (Cansi et. al. 2011). A prevalência estimada da parasitose nessa região do Brasil é de 1,42\% (Borges et. al. 2007). Em um estudo retrospectivo realizado no Rio Grande do Sul, a prevalência da parasitose foi de 
0,3\% (Rissi et. al. 2010). Na região de Patos, Paraíba, onde há predomínio de rebanho caprino, essa doença não tem sido diagnosticada (Portela et. al. 2010).

Perdas econômicas significativas são associadas a esse parasita, chegando a 4,6 $\mathrm{kg}$ de carne e $10 \%$ da produção leiteira dos animais infestados (Abo-Shehada et. al. 2003). A oestrose, por ser uma doença que geralmente não causa a morte dos animais e os produtores conhecerem os sinais clínicos, a mesma não é diagnosticada frequentemente nos laboratórios de diagnóstico (Portela et. al. 2010). O tratamento e consequente eliminação das larvas pode diminuir a observação das mesmas na necropsia, provavelmente as perdas causadas por essa parasitose são mais significativas do que sugerido pelos estudos no Brasil (Borges et. al. 2007, Portela et. al. 2010, Cansi et. al. 2011).

As fêmeas adulta de $O$. ovis são lavíparas, e depositam as larvas de primeiro instar (L1), em voos rápidos, ao redor das narinas dos ovinos. Essas larvas penetram ativamente na cavidade nasal, migrando na região do septo nasal e conchas nasais para o osso etmoide, onde sofrem a primeira ecdise para larvas de segundo instar (L2), que migram para seios nasais onde ocorre a segunda ecdise para larva de terceiro instar (L3). Essas larvas irão ser expelidas por espirros, meneios de cabeça ou de maneira espontânea e no solo evoluem para pupa e posteriormente mosca. O período de pupa dura de três a oito semanas (Ylma \& Dorchies 1991, Jacquiet et. al. 2005, Ramos, 2006). As larvas conseguem migrar de um lado da cavidade nasal para o outro, essa passagem ocorre provavelmente pelas coanas e é um meio da larva evitar as reações inflamatórias mais intensas (Yacob et. al. 2004b). A mosca adulta apresenta um aparelho bucal rudimentar e não é capaz de se alimentar, durante a fase larval no hospedeiro é necessário o acúmulo de nutrientes em quantidade suficiente para a vida livre (Suárez et. al. 2005).

Logo após a migração de L1 na cavidade nasal, ocorre ativação da resposta inflamatória. As larvas desse parasita não são hematófagas, se alimentam de mucina, albumina e colágeno, presentes na membrana basal, e também de proteínas plasmáticas e anticorpos, que estão exsudando devido o processo inflamatório. A irritação se dá, pois as larvas de O. ovis possuem pequenos espinhos na face ventral, que causam irritação mecânica e possuem a capacidade de sintetizar e excretar proteases gerando a rinite parasitária subsequente (Tabouret et. al. 2003).

Há uma resposta imune específica no local, com ação de IgA e IgG, e também sistémica, com participação de IgG. A produção sistêmica de IgG permite determinar sorologicamente se o animal teve contato com o parasita, porém não avalia se a parasitose ainda está em curso, pois mesmo após eliminação das larvas é possível observar altos níveis de IgG 
circulante (Jacquiet et. al 2005, Angulo-Valadez et. al. 2008). Provavelmente exista uma correlação negativa entre produção de IgG e estabelecimento e crescimento das larvas (AnguloValadez et. al. 2008). Para determinar se a parasitose está em curso é necessário dosar IgM, mas ainda é preciso fazer uma correlação entre os níveis de IgM e a presença das larvas (Suárez et. al. 2005).

Além da resposta imune humoral, ocorre também recrutamento de eosinófilos e mastócitos para a mucosa das vias aéreas superiores (Nguyen et. al. 1999, Tabouret et. al. 2003, Yacob et. al. 2004b). Os papéis dessas respostas na regulação da população de $O$. Ovis ainda não são esclarecidos, mas sabe-se que animais imunossuprimidos apresentam maior sobrevivência de larvas após a infestação artificial (Marchenko \& Marchenko, 1989) e animais previamente imunizados com produtos secretados pelas larvas L3 não apresentaram proteção contra o estabelecimento das larvas, mas ocorre inibição do crescimento das mesmas (Frugère et. al. 2000).

A taxa de estabelecimento das larvas é baixa $(11,2 \%)$, tendendo a aumentar quando ocorrem repetidas deposições de larvas no mesmo animal (Tabouret et. al 2003). Animais imunossuprimidos apresentam maiores taxas de estabelecimento e crescimento das larvas, demonstrando que a resposta imune do hospedeiro tem um papel importante no controle da população de Oestrus ovis (Jacquiet et. al. 2005).

A prevalência da doença geralmente é maior em animais adultos, no entanto, nem sempre a idade é um importante fator de risco para a oestrose, sugerindo que a imunidade adquirida contra o parasita é falha (Gabaj et. al. 1993, Caracappa et. al. 2000, Dorchies et. al. 2000, Murguía et. al. 2000, Scala et. al. 2001, Alcaide et. al. 2003, Angulo-Valadez et. al. 2009, Arslan et. al. 2009, Shorijeh et. al. 2011, Attindehou et. al. 2012).

Os animais de focinho preto tem uma maior probabilidade de adquirir a oestrose quando comparados com os animais de focinho manchado ou claro (Murguía et. al. 2000, Arslan et. al. 2009, Cansi et. al. 2011). Acredita-se que a atração da mosca adulta pela narina escura está interligada a conservação da temperatura por esta coloração, mantendo a temperatura ideal para o desenvolvimento do parasita (Murguía et. al. 2000).

A prevalência da oestrose em caprinos tende a ser menor que em ovinos (Gabaj et. al. 1993, Dorchies et. al. 2000, Attindehou et. al. 2012). Em caprinos a evolução do parasita é mais rápida, principalmente na época do verão europeu, o que pode dificultar a visualização das larvas (Dorchies et. al. 2000).

Apesar de preferir locais quentes e secos, a larva de Oestrus ovis tem a capacidade de adaptar seu ciclo de desenvolvimento de acordo com as características climáticas 
do local. Em épocas frias e úmidas ela retarda o desenvolvimento larval, permanecendo maior período como L1 na cavidade do hospedeiro, fenômeno chamado diapausa. Larvas de Oestrus ovis podem parasitar a cavidade nasal de ovelhas durante todo o ano, com aumento do estágio larval L1 nos meses de maior precipitação pluviométrica e pequenas quantidades de larvas L3 durante todo o período (Scala et. al. 2001). A manutenção da larva do parasita, em diversos estágios, ocorre durante todos os meses do ano em diversas partes do mundo (Ylma \& Dorchies 1991, Gabaj et. al. 1993, Dorchies et. al. 2000, Alcaide et. al 2005, Arslan et. al 2009, Attindehou et. al. 2012).

Em caprinos no sudoeste da Espanha o período favorável para o desenvolvimento das larvas é de fevereiro a setembro. (Alcaide et. al. 2005). Na Itália foi observada diapausa do parasita entre outubro e fevereiro, a fase de ciclo livre entre maio e setembro e fase larval no hospedeiro entre março e setembro (Suárez et. al. 2005). No Planalto Catarinense as larvas de $O$. ovis estão presentes em ovinos com maiores intensidades na primavera e verão, quando as temperaturas variaram entre $12^{\circ} \mathrm{C}$ e $20^{\circ} \mathrm{C}$, com tendência de aumento da umidade (Ramos et. al. 2006). Existe uma maior probabilidade de infestação e reinfestação em rebanhos maiores e quando há maior densidade populacional (Alcaide et. al. 2005).

As larvas são encontradas com frequência nos seios frontais, cavidade nasal e meato nasal (Ylma \& Dorchies 1991, Gabaj et. al 1993, Arslan et. al. 2009). Oestrus ovis não tem característica de se manter aglomerado como outras miíases, provavelmente no intuito de diminuir a reação inflamatória local, podendo permanecer no hospedeiro por mais tempo (Lutz, 1917). As lesões são geralmente mais severas em animais que apresentam seis ou mais larvas na cavidade nasal e imediatamente após o desenvolvimento da larva para L2 e L3 (AnguloValadez et. al. 2009, Angulo-Valadez et. al. 2011).

$\mathrm{Na}$ doença são frequentes rinites e sinusites nos hospedeiros, com a presença de secreção nasal mucoide, purulenta ou piohemorrágica (Tabouret et. al. 2003, Angulo-Valadez et. al. 2009, Alem et. al. 2010, Angulo-Valadez et. al. 2011). Os espirros e secreção nasal são considerados os sinais clínicos mais prevalentes na oestrose. Em alguns casos, pode ocorrer obstrução das vias aéreas, interferindo na alimentação e tempo de ruminação, gerando déficit nutricional e diminuição na produção (Alcaide et. al. 2005, Angulo-Valadez et. al. 2011). O animal também pode apresentar apatia, tosse, ataxia, epistaxe e incoordenação motora, também pode ser observada pneumonia, devido a infecções secundárias (Dorchies, 1997, Alcaide et. al. 2005). 
Alguns ovinos e caprinos não apresentam sinais clínicos, mesmo com a presença do parasita na cavidade nasal. Em contraste, alguns indivíduos apresentam sinais clínicos severos mesmo com poucas larvas de Oestrus ovis. A ausência de sinais clínicos no hospedeiro pode caracterizar uma imuno tolerância do animal ao parasita, no intuito de diminuir os danos causados, demonstrando uma melhor relação hospedeiro-parasita. Já a presença de sinais clínicos graves em animais com poucas ou nenhuma larva pode ocorrer mesmo após as larvas abandonarem o hospedeiro (Jacquiet et. al. 2005).

Esses achados contraditórios sugerem que exista uma variação genética que determine resistência e susceptibilidade das ovelhas a oestrose (Angulo-Valadez et. al. 2008) e que uma variação genética ou antigênica das larvas possa influenciar a manifestação clínica nos hospedeiros (Grisez-Duranton et. al. 2002, Angulo-Valadez et. al 2011).

O desenvolvimento do parasita em um hospedeiro não específico gera uma resposta inflamatória mais exacerbada do hospedeiro, o que reflete maiores sinais clínicos e um aumento de prevalência, pelo aumento da facilidade de detectar a doença. O fato dos caprinos apresentarem menor taxa de parasitismo, com evolução mais rápida da larva e sinais clínicos mais brandos pode sugerir que a mosca de Oestrus ovis se adaptou posteriormente aos ovinos e por isso nesses animais os sinais clínicos são mais exacerbados, devendo ocorrer novos estudos para elucidar a relação hospedeiro-parasita nesses dois hospedeiros (Dorchies et. al. 2000).

Infecções concomitantes de Oestrus ovis e tricostrongilos no trato gastrointestinal demonstram alteração na patogenicidade desses parasitos em pequenos ruminantes. Observações e estudos experimentais sugerem que interações negativas podem ocorrer apesar das diferenças em localizações anatômicas, há uma diminuição na eliminação de larvas e na população de tricostrongilos intestinais, mas não há interferência no estabelecimento e crescimento das larvas de Oestrus ovis (Dorchies et. al. 1997, Jacquiet el. al. 1999, Yacob et. al. 2004a). Acredita-se que essa interação entre as populações ocorra devido ao tipo de resposta que ambos estimulam no animal, promovendo uma migração de leucócitos em geral, principalmente eosinófilos e mastócitos, em todas as mucosas (Yacob et. al. 2002, Yacob et. al. 2004a, Yacob et. al. 2004b).

A grande expansão da ovinocultura pode favorecer um aumento da oestrose nos territórios brasileiros. Sabe-se que quanto maior a população de ovinos e caprinos maior a chance de sua ocorrência. 
CAPÍtUlo II 


\section{DOENÇAS DA CAVIDADE NASAL EM PEQUENOS RUMINANTES NO DISTRITO FEDERAL E ENTORNO}

\section{1- RESUMO}

\section{DOENÇAS DA CAVIDADE NASAL EM PEQUENOS RUMINANTES NO DISTRITO} FEDERAL E ENTORNO: Vanessa da Silva Mustafa, doutaranda em Ciências Animais pela Universidade de Brasília; Márcio Botelho de Castro, professor doutor da Universidade de Brasília, Brasília/DF. A ovinocultura e caprinocultura apresenta intenso crescimento na região central do Brasil. A baixa condição sanitária dos rebanhos brasileiros e o transporte desorganizado de animais entre as regiões favorece que doenças se disseminem pelo território nacional. As rinites parasitárias, micótica e oomicóticas são doenças de baixa prevalência mas que provocam prejuízos significativos. Foi realizado levantamento dos laudos do Laboratório de Patologia Veterinária da Universidade de Brasília (LPV-UnB) nos anos de 2003 a 2014 para verificar a ocorrência da oestrose, pitiose rinofacial e conidiobolomicose em ovinos e caprinos. Foi observada uma prevalência de oestrose em 4,08\% dos pequenos ruminantes, sendo $86,36 \%$ ovinos e 13,64\% de caprinos. A maioria dos casos ocorreu na época das secas. Os animais apresentavam secreção nasal, dispneia e apatia. Apesar de não ser correlacionada com a morte dos animais, essa parasitose causa diminuição marcante na produção animal. Quatro surtos de rinite micótica ou oomicótica foram observados no Distrito Federal e Goiás. O agente etiológico foi identificado por reação da polimerase em cadeia ou por imuno histoquímica, como Pythium insidiosum em dois surtos no DF e Conidiobolus lamprauges nos demais. A pitiose rinofacial apresentou morbidade de 7,27\% com letalidade de 75\%. Nos surtos de conidiobolomicose no estado de Goiás foi observada morbidade de 4,28\% a 7,39\% com letalidade de $100 \%$. Os sinais mais comuns são dispneia, secreção nasal e apatia. Durante a necropsia observou-se tecido de granulação necrótico na cavidade nasal, localizada em região rinofacial, nos casos de pitiose, ou na região rinofaríngea, nos casos de conidiobolomicose. A importância dessas rinites vem aumentando na região, devido aumento no rebanho ovino e falta de conhecimento a prevenção. O conhecimento das rinites causadas por diferentes agentes permite o diagnóstico diferencial e possibilita a recomendação medidas de controle e profilaxia. É a primeira vez que essas doenças são descritas nesses estados.

Termos de indexação: Rinite parasitária, rinite micótica, rinite fúngica, Conidiobolus lamprauges, Pythium insidiosum, Oestrus ovis. 


\begin{abstract}
DISEASES OF NASAL CAVITY IN SMALL RUMINANT IN THE DISTRITO FEDERAL AND SURROUNDING: Vanessa da Silva Mustafa, doutaranda em Ciências Animais pela Universidade de Brasília; Márcio Botelho de Castro, professor doutor da Universidade de Brasília, Brasília/DF. The goat and sheep industry show strong growth in central Brazil. The low health status of Brazilian herds and disorganized transport of animals between regions that favors disease from spreading throughout the Brazil. As rinites parasitárias, micótica e oomicóticas são doenças de baixa prevalência mas que provocam prejuízos significativos. A retrospective data collection of necropsy and histopathology cases performed at the Veterinary Pathology Laboratory of University of Brasília (LPV-UnB) from 2003 to 2012 was done to verify the occurrence of oestrose, pythiosis rhinofacial and conidiobolomycosis in sheep and goats. It was observed a $4.08 \%$ prevalence of parasitized animals, of which $86.36 \%$ were ovine and $13.64 \%$ were caprine. The majority of the cases occurred during the dry season. The animals presented lethargy, nasal discharge, diarrhea and dyspnea. Although oestrosis is not an important cause of death in sheep, the economic losses related to nasal cavity irritation and decrease in food intake can generate even more significant losses than what is expected. Four outbreaks of mycotic or oomycotic rhinitis were observed in Distrito Federal (DF) and Goiás. The etiologic agent was identified by polymerase chain reaction or by immunohistochemistry as Pythium insidiosum in two outbreaks in DF and Conidiobolus lamprauges in the other two. The rhinofacial pythiosis presented $7.27 \%$ of morbidity and $75 \%$ of lethality in DF outbreaks. In the state of Goiás outbreaks, it was observed morbidity of $4.28 \%$ to $7.39 \%$ with $100 \%$ lethality. The affected animals presented dyspnea, purulent or serosanguinous nasal discharge and lethargy. The main lesion consisted of severe and extensive necrosis in the nasal cavity, located on rhinofacial region in pythiosis cases, or on rhinopharyngeal region in sheep with conidiobolomycosis. The importance of these rhinitis is increasing in the region due to increased herd sheep and lack of knowledge on prevention. Knowledge of rhinitis caused by different agents allows the differential diagnosis and possible recommendation for control and prevention measures. It is the first time that these diseases are described in these states.
\end{abstract}

Indexing terms: Rhinitis parasitic, mycotic rhinitis, fungal rhinitis, Conidiobolus lamprauges, Pythium insidiosum, Oestrus ovis. 


\section{2- INTRODUÇÃO}

As rinites dos ruminantes são um grupo heterogêneo de doenças que causam sinais semelhantes. O conhecimento das rinites causadas por diferentes agentes e de outras enfermidades não inflamatórias, como as neoplasias, e o seu diagnóstico diferencial é importante para que possam ser recomendadas medidas de controle e profilaxia (Portela et. al. 2010).

Rinites granulomatosas com alta letalidade são associadas a fungos e oomicetos em pequenos ruminantes (Riet-Correa et. al 2008). O hábito de pastejo baixo dos ovinos pode favorecer a contaminação através da inalação dos agentes que se encontram em matéria vegetal próxima a locais alagadiços (Silva et al. 2007b). Apesar de possuir distribuição mundial, sua frequência é baixa, refletindo-se no pouco conhecimento destas doenças (Carrigan, 1992, Santurio et. al. 1998, Morris et. al. 2001).

Os principais agentes envolvidos na rinite granulomatosa em pequenos ruminantes são os fungos do gênero Conidiobolus spp. e o oomiceto Pythium insidiosum (Silva et. al. 2007a, Moraes et. al. 1997, Riet-Correa et. al. 2008, Aguiar et. al. 2014). Conidiobolomicose (zigomicose ou murcomicose) é uma doença emergente granulomatosa associada ao quadro de rinite em humanos e animais (Tadano et. al 2005, Santurio et. al. 2006, Boabaid et. al. 2008, Riet-Correa et. al. 2008, Souza et. al 2013). A pitiose é associada principalmente ao quadro de dermatite granulomatosa, podendo acometer também a cavidade nasal de ovinos (Leal et. al. 2001b, Headley \& Junior 2004, Tabosa et. al. 2004, Santurio et. al. 2006, Gabriel et. al. 2008, Galiza et. al. 2014). Dentre as doenças micóticas e oomicóticas a pitiose é a de maior prevalência e a zigomicose é a principal micose diagnosticada em ruminantes (Galiza et. al. 2014a).

Em ovinos a conidiobolomicose afeta a região etmoidal, conchas nasais, seios paranasais, coanas e nasofaringe, podendo se estender para a órbita, causando exoftalmia, para a região anterior do cérebro através da placa cribiforme e pulmão (Carrigan et. al. 1992, Morris et. al. 2001, Silva et. al. 2007a, Boabaid et. al. 2008, Riet-Correa et. al. 2008, Ubiali et. al. 2013, Aguiar et. al. 2014). A forma rinofacial causa deformidade facial com necrose e fistulas em junções mucoepitelial, palato duro e septo nasal na região média e rostral da cavidade nasal, pode causar linfadenopatia regional e lesão em pulmão, essa apresentação clínica é atribuída a Pythium insidiosum (Santurio et al. 2007, Portela et. al. 2010, Ubiali et. al. 2013, Aguiar et. al. 2014). 
Microscopicamente, a conidiobolomicose causa lesão granulomatosa multifocal e na pitiose observa-se acentuada necrose caseosa (Ubiali et. al. 2013). Em ambas no centro necrótico observam-se hifas raramente septadas e com ramificações laterais, sendo rodeadas por reação de Splendore-Hoeppli (Riet-Correa, 2007). As hifas do Conidiobolus spp. são mais largas, com paredes finas e com contornos não paralelos, enquanto as hifas de Pythium insidiosum são mais delgadas, com paredes mais espessas e menor intensidade de reação de Splendore-Hoeppli ao redor (Leal et. al 2001a, Santurio et. al. 2006, Boabaid. et. al. 2008, Portela et. al 2010).

Oestrus ovis é um parasita cosmopolita que afeta ovinos e caprinos e possui moderado potencial zoonótico (Pampiglione et. al. 1997, Murguía et. al. 2000). É endêmica em países de clima quente e seco (Suárez et. al. 2005), e o crescimento desorganizado dos rebanhos caprinos e ovinos e a importação de animais propiciam a sua expansão (Pinheiro et. al. 2000, Guimarães, 2006). Foi descrita pela primeira vez no Brasil em 1916, no Rio de Janeiro, onde foi observada sintomatologia clínica em dois carneiros importados da Europa (Lutz, 1917).

Os animais parasitados apresentam secreção nasal, espirros frequentes, incoordenação motora ou andar em círculos e dispneia (Caracappa et. al. 2000, Alcaide et. al 2005). O efeito patogênico do Oestrus ovis é frequentemente subestimado (Pampiglione et. al. 1997). No entanto, perdas econômicas significativas são associadas a esse parasita, chegando a 4,6 kg de carne e $10 \%$ da produção leiteira nos animais infestados (Abo-Shehada et. al. 2003).

Existe uma maior probabilidade de infestação e reinfestação em rebanhos maiores e quando há maior densidade populacional (Alcaide et. al. 2005), como a população de ovinos tem apresentado aumento significativo no DF nos últimos anos a prevalência da oestrose pode aumentar nessa região (IBGE, 2009). As descrições de oestrose em pequenos ruminantes no Brasil central são escassas (Borges et. al. 2007, Cansi et. al 2011) e pouco se conhece sobre sua epidemiologia nessa região.

O presente trabalho descreve a ocorrência de conidiobolomicose, pitiose rinofacial e oestrose na região de atuação do laboratório de patologia veterinária da Universidade e Brasília, relatando a sazonalidade dessas doenças, aspectos clínicos e anatomopatológicos observados na região, visando fornecer subsídios para estabelecimento de medidas preventivas minimizando as perdas econômicas causadas por essas doenças. 


\section{3- MATERIAL E MÉTODOS}

Foi realizado estudo retrospectivo nos arquivos de necropsia e exames histopatológicos do Laboratório de Patologia Veterinária da Universidade de Brasília (LPVUnB) no período de 2003 a 2012. Os laudos de ovinos e caprinos foram revisados para identificar casos com descrição de larvas de Oestrus ovis e os laudos com o diagnóstico de rinite micótica ou oomicótica foram reavaliados. Experimentos externos ou casos inconclusivos foram excluídos para cálculos de morbidade e letalidade.

Informações sobre o tamanho do rebanho, número de animais acometidos, número de mortes, idade dos animais, pelagem, época do ano de ocorrência dos casos, sinais clínicos, evolução clínica entre outras foram coletadas a partir dos laudos ou das atas de visita às propriedades. A morbidade e a letalidade foram calculadas a partir dessas informações e comparadas com os mesmos índices calculados a partir de estudos publicados anteriormente no Brasil.

Os animais necropsiados tiveram os órgãos analisados minuciosamente e colhidas amostras de órgãos em formol a 10\% tamponado $\mathrm{pH} 7.0$, processadas rotineiramente, incluídos em parafina, realizados cortes histológicos na espessura de $5 \mu \mathrm{m}$, corados com hematoxilina e eosina (HE) e analisados em microscopia de luz. Para caracterização do agente infeccioso nas lesões foi utilizada a coloração de prata metenamina de Grocott (GMS) nas lâminas histopatológicas permitindo a visualização das hifas.

Para identificação do agente das rinites granulomatosas foi utilizado reação da polimerase em cadeia (PCR) ou imuno-histoquímica (IHQ).

A PCR foi realizada com fragmentos frescos de tecido a extração de DNA foi feita utilizando fenol:clorofórmio:álcool isoamílico. O produto da extração era submetido a um PCR com um primer universal para fungo e depois com primer específico para Conidiobolus lamprauges, ambos baseados no gene 18S ribossomal (GenBank GQ478281.1). Foram analisados oito microlitros do produto da PCR por eletroforese em gel de agarose a $1 \%$ corados com brometo de etídio. Água ultra pura foi utilizada como controle negativo (Silveira et. al. 2013).

Para a técnica de IHQ foram utilizadas lâminas silanizadas com seções histológicas de $3 \mu \mathrm{m}$. Após a desparafinização e reidratação dos tecidos, foi realizado o bloqueio da peroxidase endógena através do uso de peróxido de hidrogênio (10 volumes), seguido da recuperação antigênica com solução de TRIS-EDTA ( $\mathrm{pH} 9,0)$ em forno micro-ondas em potência máxima por 10 minutos. O bloqueio das reações inespecíficas foi realizado com 
solução de caseína (30 minutos em temperatura ambiente). Como anticorpo primário foi utilizado um anticorpo policlonal (não comercial) anti-Pythium insidiosum produzido em coelho, diluído (1:1000) em PBST. O anticorpo secundário biotinilado e o complexo estreptavidinaperoxidase (LSAB+System-HRP, Dako Cytomation, K0690) ou estreptavidinafosfatase alcalina (LSAB+System-AP, Dako Cytomation, K0689) foram utilizados consecutivamente, incubados à temperatura ambiente por 30 minutos, e marcados através da adição do cromógeno de tetracloreto de 3-3'diaminobenzidina (DAB, Sigma D-5637) ou Liquid Permanent Red (Dako Cytomation, K0640), respectivamente. As seções histológicas foram contra coradas com hematoxilina de Harris ou de Mayer. Como controle positivo foram utilizadas seções histológicas de caso confirmado de pitiose equina. Como controles negativos foram utilizadas as mesmas seções a serem testadas, com a substituição do anticorpo primário por diluente de anticorpo (PBST) (Gabriel et. al. 2008).

Os valores mensais referentes ao índice pluviométrico médio (IPVM) foram calculados a partir dos dados obtidos junto ao Instituto Nacional de Meteorologia (INMET), baseados no levantamento histórico feito pelo instituto. Esses valores consistem da normal climatológica da região, que são as médias de dados climatológicos calculadas para o período. 


\section{4- RESULTADOS}

No período de 2003 a 2012 foram realizados 6017 necropsias e histopatológicos pelo LPV-UnB, desses 814 eram de pequenos ruminantes (13,53\%). Sendo 711 ovinos e 103 caprinos. Desse total, 127 animais (122 ovinos e cinco caprinos) eram animais de projetos externos e 149 animais (126 ovinos e 23 caprinos) não tiveram seus laudos conclusivos e foram removidos do estudo. Restando para análise um total de 538 animais, 463 (86,06 \%) ovinos e $75(13,94 \%)$ caprinos.

Nesse período seis ovinos $(6 / 4631,29 \%)$ foram necropsiados e tiveram a causa da morte concluída como rinite granulomatosa micótica ou oomicótica. Os animais eram provenientes de três propriedades, duas delas foram visitadas na época dos casos. Foi realizada investigação nas propriedades vizinhas, e uma delas, relatou ocorrência de casos de rinite granulomatosa, com característica similar a dos outros surtos, totalizando quatro propriedades.

Vinte e dois animais $(4,08 \%)$ apresentaram infestação por larvas de Oestrus ovis, sendo 19 ovinos $(86,36 \%)$ e 3 caprinos $(13,64 \%)$.

\section{1- Pitiose rinofacial}

Dois surtos ocorreram no ano de 2007, com início dos sinais clínicos em janeiro e fevereiro. Em um dos surtos o animal foi tratado por cinco meses, sendo encaminhado para necropsia em maio. No segundo surto quatro animais apresentaram sinais clínicos de um total de 55 animais (7,27\%), um desses animais foi tratado e sobreviveu. Os demais foram necropsiados. A evolução clínica variou de 13 a 60 dias, os animais tinham entre 12 e 18 meses de idade, fêmeas, da raça Santa Inês.

Os animais apresentavam aumento de volume na região nasal (4/4 100\%) (figura 1A) e lábio superior (1/4 25\%), dispneia (3/4 75\%), espirros (1/4 25\%), secreção nasal purulenta $(1 / 425 \%)$ e sanguinolenta (1/4 25\%) e posição ortopnêica (1/4 25\%).

$\mathrm{Na}$ necropsia dos quatro animais foi observada lesão granulomatosa, de coloração pálida-amarelada, aspecto friável, fétida, que se estendia das fossas nasais a porção rostral das conchas nasais, com áreas multifocais de necrose (figura 1C). Nos animais do segundo surto foi observada lesão granulomatosa em glândula parótida e linfonodos regionais. Em um animal, também do segundo surto, foi observada lesão granulomatosa no pulmão. Havia também espessamento do tecido subcutâneo e derme na região nasal rostral.

Microscopicamente nos fragmentos da cavidade nasal foi observado infiltrado acentuado de macrófagos, com quantidade discreta a moderada de células gigantes 
multinucleadas e células epitelioides. Presença moderada a acentuada de polimorfonucleares, que encontravam-se ao redor de áreas de necrose. Em meio aos centros necróticos haviam imagens negativas de hifas circundadas por reação de Splendore-Hoeppli em quantidade discreta a moderada, ou ausente (figura 2A). Essa mesma lesão foi observada em fragmentos de glândula parótida, linfonodos regionais e nódulos pulmonares. Na coloração de GMS visualizou-se hifas pobremente septadas, com paredes espessas e irregulares e presença de dilatação balonosa na extremidade (figura 2C). O exame imuno-histoquímico pela técnica da imunoperoxidase com o anticorpo anti-Pythium insidiosum demonstrou reação positiva e específica para esse oomiceto (figura 2D).

Os índices de morbidade e letalidade, apresentação clínica e curso clínico desses surtos estão resumidos na tabela 1, que apresenta dados de descrições da enfermidade no Brasil para comparação.

Tabela 1: Comparação dos dados de morbidade, letalidade, quadro clínico e curso clínico da pitiose em cavidade nasal em ovinos no Brasil.

\begin{tabular}{|c|c|c|c|c|c|}
\hline Ref. & $\mathbf{U F}$ & $\operatorname{MB}(\%)^{*}$ & $\mathbf{L T}(\%) *$ & $\mathbf{A C}$ & $\mathbf{C C} *$ \\
\hline Presente estudo (2014) & $\mathrm{DF}$ & 7,27 & 75 & Rinofacial & $13-180$ \\
\hline Riet-Correa et. al. (2008) & $\mathrm{PB}$ & 2,5 & 100 & Rinofacial & 14 \\
\hline Saturnino et. al. (2008) & MT & & 100 & Rinofacial & $28-50$ \\
\hline Portela et. al. (2008) & PB & 1,08 & 0 & Rinofacial & \\
\hline Carrera et. al. (2013) & PE e BA & 23,2 a 45 & & Rinofacial & \\
\hline
\end{tabular}




\section{2- Conidiobolomicose}

Em maio de 2010 ocorreu o terceiro surto de rinite granulomatosa na área de atuação do LPV-UnB, na cidade de Flores, estado de Goiás. A fazenda apresentava como foco principal a produção de arroz irrigado, e após a colheita dos grãos, os animais eram soltos nas áreas de resteva. Anteriormente, nessa propriedade ocorreram casos de pitiose cutânea em equinos. Dos 230 ovinos criados na propriedade, 17 adoeceram e todos morreram. A primeira morte ocorreu em janeiro e o surto durou até maio de 2010. O curso clínico da doença era de aproximadamente 10 dias. Dois animais dessa propriedade foram necropsiados. Os animais apresentaram o sinal clínico em piquetes diferentes e não havia comunicação entre os canais de água.

O levantamento epidemiológico realizado em propriedades vizinhas identificou um quarto surto em uma fazenda onde a criação de ovinos ocorria em condições semelhantes. O rebanho era formado por 140 animais, e seis morreram com o mesmo quadro clínico observado no terceiro surto. As mortes ocorreram nos meses de janeiro e fevereiro de 2010. A atividade principal da propriedade também era a produção de arroz irrigado. Durante a visita não havia animais doentes, o diagnóstico foi baseado na epidemiologia e sinais clínicos relatados.

Os índices de morbidade e letalidade, apresentação clínica e curso clínico desses surtos estão resumidos na tabela 2, que apresenta dados de descrições anteriores publicados no Brasil para comparação. 
Tabela 2: Comparação dos dados de morbidade, letalidade, apresentação clínica e curso clínico da rinite por conidiobolomicose em ovinos no Brasil.

\begin{tabular}{cccccc}
\hline Ref. & UF & MB (\%)* & LT (\%)* & AC & CC* \\
\hline Presente estudo (2014) & GO & $4,3-7,4$ & 100 & Rinofaríngea & 10 \\
Portela et. al. (2010) & PB & $1,25-20,0$ & 100 & Rinofaríngea & $1-120$ \\
Furlan et. al. (2010) & SC & 8,0 & 100 & Rinofaríngea & \\
Pedroso et. al. (2009) & RS & 13,3 & 100 & Rinofaríngea & \\
Boabaid et. al. (2008) & MT & 30,0 & 100 & Rinofaríngea & $7-35$ \\
Riet-Correa et. al. (2008) & PB & $1,25-11,6$ & 100 & Rinofaríngea & $15-180$ \\
Silva et. al. (2007) & PI & 2,8 & 100 & Rinofaríngea & $7-35$ dias \\
\hline
\end{tabular}

$\mathrm{MB}=$ morbidade; $\mathrm{LT}=$ Letalidade; $\mathrm{AC}=$ Apresentação clínica; $\mathrm{CC}=$ curso clínico em dias.

* Valores calculados com base nos dados publicados. Dados em branco não foram possíveis de serem calculados com as informações publicadas.

Clinicamente foi observada respiração ruidosa e dispneia, secreção nasal que variava de mucopurulenta a sanguinolenta, apatia e exoftalmia (figura 1B). O quadro clínico sempre culminava com a morte dos animais.

Durante a necropsia o principal achado foi massa de coloração pálida, consistência friável, com áreas de necrose multifocais, comprometendo nasofaringe, conchas nasais e septo nasal com área de osteólise multifocal em toda cavidade nasal. Essa lesão era observada também na região peribulbar causando exoftalmia e se estendia do terço médio da cavidade nasal à placa cribriforme do osso etmoide (figura 1D). O osso etmoide apresentavase elevado com múltiplas áreas arredondadas firmes e amareladas. Linfadenopatia regional foi observada nos dois animais.

No pulmão de um animal havia quantidade acentuada de nódulos multifocais, pálidos, com halo avermelhado, de consistência firme, superfície lisa e brilhante (figura 1E). E foram observadas lesões puntiformes firmes e amareladas no córtex frontal do cérebro (figura 1F). Ao corte observava-se continuidade entre a lesão da cavidade nasal e da região cortical. $\mathrm{Na}$ base da língua havia uma lesão ulcerativa de $3 \mathrm{~cm}$ de diâmetro. No terço inicial do intestino delgado havia uma área ulcerada de aproximadamente $3 \mathrm{~cm}$ de diâmetro. 
Microscopicamente o fragmento das conchas nasais apresentava acentuado infiltrado de macrófagos, com quantidade acentuada de células epitelioides e células gigantes multinucleadas. Em meio ao infiltrado observou-se imagens negativas de hifas fúngicas, circundadas por marcada reação de Splendore-Hoeppli e múltiplos focos de necrose em quantidade moderada a acentuada (figura 2B). A mesma lesão foi observada em pulmão, língua, linfonodo e intestino delgado.

No animal com comprometimento encefálico, haviam focos de infiltrado histiocítico moderado e necrose, com presença de hifas intralesionais no córtex frontal e parietal. Nas meninges foi observado infiltrado neutrofílico e histiocítico moderado com imagens negativas de hifas intralesionais, necrose vascular moderada e formação de trombos.

A coloração de GMS permitiu a visualização de hifas com paredes finas, pobremente septadas, com dilatação balonosa na extremidade (Figura 9). Os fragmentos de conchas nasais, córtex frontal, pulmão, linfonodos e intestino foram enviados para reação da polimerase em cadeia (PCR) onde foi identificado Conidiobolus lamprauges (Silveira et. al. 2013).

As principais alterações clínicas, achados anatomopatológicas e histopatológicos encontradas nos ovinos necropsiados nos surtos de pitiose rinofacial e conidiobolomicose estão resumidas na Tabela 3. 
Tabela 3: Sinais clínicos, achados anatomopatológicos e agentes etiológicos em ovinos acometidos por pitiose rinofacial e conidiobolomicose no Distrito Federal e Goiás. (Brasília, 2014)

\begin{tabular}{|c|c|c|c|c|c|c|c|c|c|c|c|c|c|c|}
\hline \multirow{2}{*}{ Animal } & \multicolumn{3}{|c|}{ Sinais clínicos } & \multicolumn{3}{|c|}{ Achados de necropsia } & \multicolumn{6}{|c|}{ Achados histopatológicos } & \multirow{2}{*}{ Surto } & \multirow{2}{*}{$\mathrm{AE}$} \\
\hline & Dispneia & SN & Apatia & Linf. & Pulmão & Exof/Face & $\mathrm{SH}$ & Nec. & Hifas & PMN & $\mathrm{M} \varnothing$ & $\mathrm{CG} / \mathrm{EP}$ & & \\
\hline 1 & + & - & - & - & - & Face & - & + & + & ++ & +++ & + & 1 & PT \\
\hline 2 & - & - & - & + & - & Face & ++ & +++ & + & ++ & +++ & ++ & 2 & PT \\
\hline 3 & - & + & - & - & - & Face & + & ++ & ++ & ++ & +++ & + & 2 & $\mathrm{PT}$ \\
\hline 4 & + & - & - & - & + & Face & + & ++ & +++ & +++ & +++ & + & 2 & PT \\
\hline 5 & + & + & + & + & - & Exof & +++ & ++ & ++ & + & +++ & +++ & 3 & CL \\
\hline 6 & + & + & + & + & + & Exof & +++ & +++ & +++ & ++ & +++ & +++ & 3 & CL \\
\hline
\end{tabular}



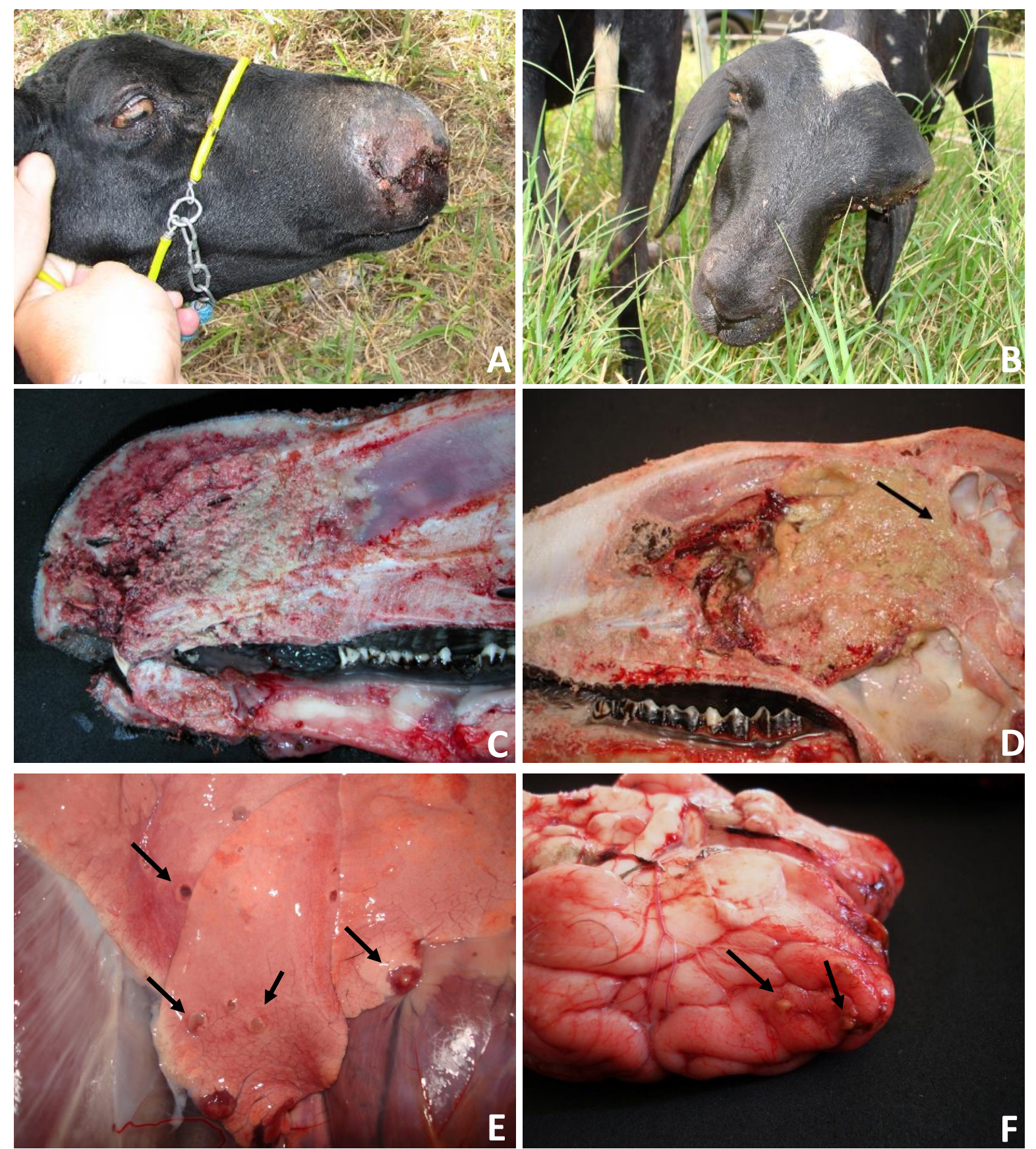

Figura 1: A) Ovino. Pitiose rinofacial Aumento de volume rostral na cavidade nasal e secreção nasal sero-sanguinolenta. B) Ovino. Conidiobolomicose rinofaríngea. Assimetria facial com marcada exoftalmia. C) Ovino. Pitiose rinofacial. Necrose extensa severa com compressão e obstrução da porção rostral da cavidade nasal. D) Ovino. Conidiobolomicose rinofaríngea. Tecido friável e necrótico situado na porção caudal da cavidade nasal e osso etmoide (seta). E) Ovino. Pulmão. Lesões nodulares granulomatosas multifocais, amareladas ou avermelhadas (seta) causadas por Conidiobolus lamprauges. F) Ovino. Cérebro. Lesões puntiformes, amareladas e firmes comprometendo córtex cerebral (seta) causada por $C$. lamprauges. 

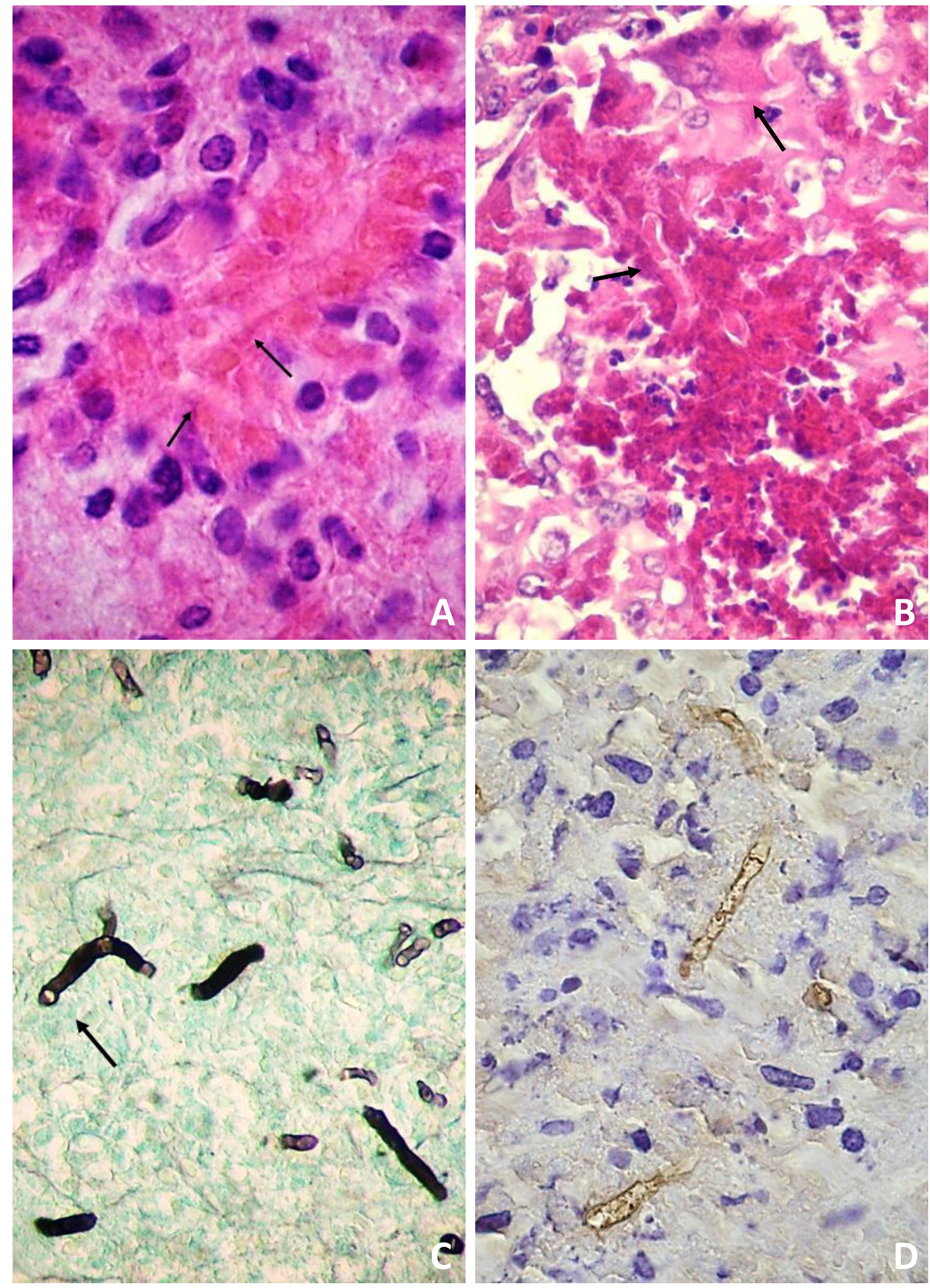

Figura 2: A) Ovino. Tecido da cavidade nasal. Pitiose rinofacial. Infiltrado granulomatoso circundando área necrótica com imagem negativa de hifa (seta) e reação de Splendore-Hoeppli. (HE. Obj. 100X). B) Ovino. Tecido da cavidade nasal. Conidiobolomicose rinofaríngea. Infiltrado granulomatoso, com grande quantidade de células gigantes multinucleadas, circundando área necrótica com imagens negativas de hifas (setas) e marcada reação de Splendore-Hoeppli. (HE. Obj. 40X) C) Ovino. Tecido de cavidade nasal. Pitiose rinofacial. Hifas raramente septadas e ramificadas com dilatação balonosa terminal (seta). (GMS. Obj. 40X). D) Ovino. Tecido de cavidade nasal. Pitiose rinofacial. Imuno-histoquímica demonstrando marcação positiva para anticorpo anti-Pythium insidiosum. (IHQ. Obj. 40X). 


\section{3- Oestrose}

Vinte e dois animais $(4,08 \%)$ apresentaram infestação por larvas de Oestrus ovis, sendo 19 ovinos $(86,36 \%)$ e 3 caprinos $(13,64 \%)$. O parasitismo dos animais foi detectado em quase todos os meses do ano, apesar da maioria dos casos estarem concentrados entre maio e agosto, meses de menor precipitação pluviométrica na região (figura 3). A temperatura média anual na região apresentou pequena variação durante o período do estudo $\left(20,6^{\circ} \mathrm{C} \pm 1,17\right)$. Os diagnósticos anatomopatológicos dos animais acometidos por oestrose encontra-se na tabela 4 .

Nos anos 2007 e 2009 foi observado o maior número de animais com a parasitose, com seis casos em cada ano. Em 2008 foi observado o parasitismo em quatro ovinos, e 2 casos no ano de 2006. Em 2004, 2010, 2011 e 2012 foi observado um ovino com a doença em cada ano. Não foram identificados casos de oestrose em 2003 e 2005 (tabela 5).

A maioria dos animais com oestrose $(59,09 \%)$ apresentava idade acima de 1,5 anos, cinco animais $(22,72 \%)$ tinham menos de 6 meses de idade e em quatro laudos essa informação não foi descrita. Dos animais parasitados, 13 (59,09\%) tinham pelagem preta, seis $(27,27 \%)$ tinham pelagem marrom e um animal $(4,54 \%)$ era branco. Em dois laudos não havia essa informação.

O número de larvas observado em cada animal durante a necropsia variou de 2 a 15 larvas, que foram encontradas com maior frequência nos seios nasais ( $n=627,27 \%$ ) (Figura 4 e 5), concha nasal $(n=418,18 \%)$ (figura 4$)$, traqueia $(n=418,18 \%)$ e seio paranasal $(n=2$ $9,09 \%$ ). Também foram visualizadas larvas em seio cornual, concha etmoidal, coanas nasais, cavidade oral e orofaringe, em apenas um animal para cada um desses locais $(4,54 \%)$.

Os principais sinais clínicos relatados foram apatia ( $n=731,82 \%)$, secreção nasal $(n=627,27 \%)$, diarreia $(n=522,72 \%)$, dispneia $(n=418,18 \%)$, emagrecimento $(n=418,18 \%)$. Espirros e andar em círculos foram observados em um animal cada (4,54\%).

No trato respiratório superior os achados mais relevantes foram sinusite $(n=3$ 13,63\%), hiperemia de conchas nasais ( $n=3$ 13,63\%) (Figura 4), secreção nasal ( $n=2$ 9,09\%) e coanas hiperêmicas ( $n=14,54 \%$ ) (Figura 4). Também foram observados consolidação do parênquima pulmonar $(n=522,73 \%)$, edema pulmonar $(n=418,18 \%)$, congestão pulmonar $(n=4$ $18,18 \%)$, caquexia ( $n=29,09 \%)$, enfisema pulmonar ( $n=29,09 \%)$. 
- IPVM

- Animais

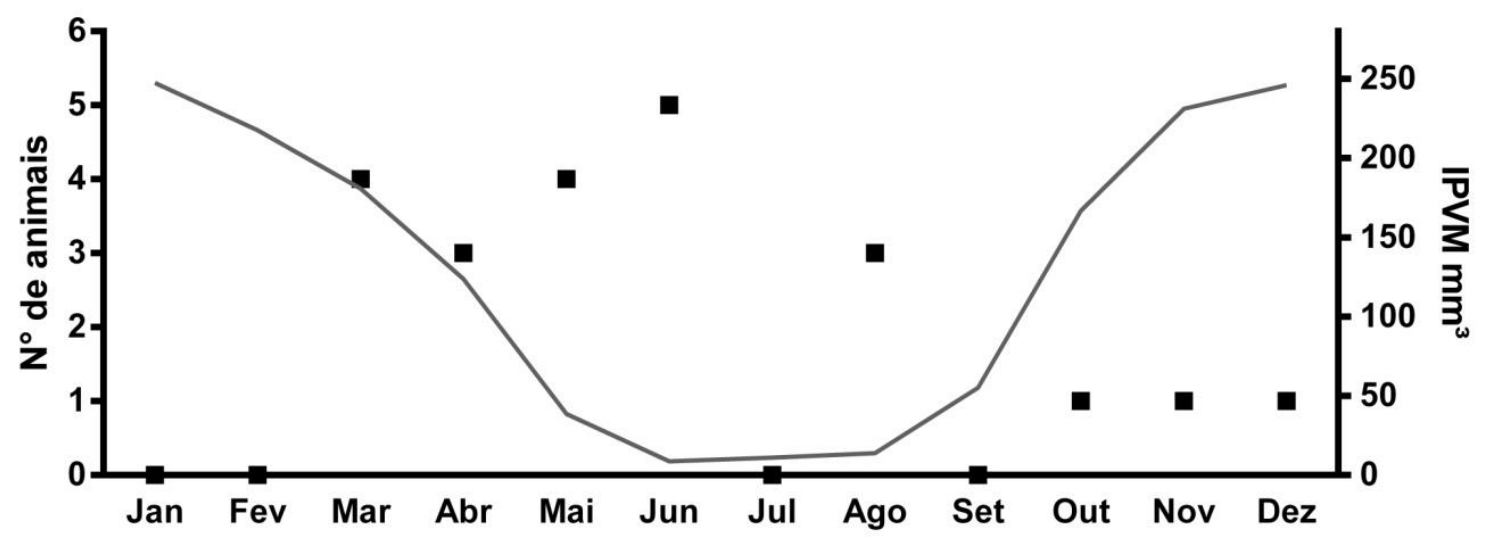

Figura 3: Distribuição do número de casos de pequenos ruminantes com oestrose quanto ao mês de registro (símbolo) e índice pluviométrico médio (IPVM) registrado durante o período de 2003 a 2012. 
Tabela 4: Diagnóstico anatomopatológico dos animais parasitados por Oestrus ovis no Distrito Federal e Entorno.

\begin{tabular}{|c|c|c|c|}
\hline Diagnóstico & $\mathbf{N}$ & Mês/ano & Localização \\
\hline \multirow{2}{*}{ Pneumonia abscedativa } & \multirow{2}{*}{2} & Junho/2007 & Não informado \\
\hline & & Nov/2007* & Vargem Bonita ${ }^{1}$ \\
\hline \multirow{4}{*}{ Broncopneumonia purulenta } & \multirow{4}{*}{4} & Março/2007 & Vargem bonita $^{1}$ \\
\hline & & Março/2008 & Vargem bonita $^{1}$ \\
\hline & & Maio/2011 & Planaltina-DF \\
\hline & & Abril/2012 & N. R. Tabatinga \\
\hline \multirow{5}{*}{ Hemoncose } & \multirow{5}{*}{5} & Maio/2004 & Não informado \\
\hline & & Abril/2007* & Padre Bernardo ${ }^{2}$ \\
\hline & & Agosto/2008 & Padre Bernardo 2 \\
\hline & & Maio/2009 & Padre Bernardo \\
\hline & & Maios/2009 & Brazlândia \\
\hline \multirow{3}{*}{ Desnutrição } & \multirow{3}{*}{3} & Junho/2007 & Não informado \\
\hline & & Junho/2009 & Padre Bernardo 3 \\
\hline & & Junho/2009 & Padre Bernardo 3 \\
\hline Miocardite & 1 & Março/2008 & N. R. Taquara \\
\hline Enterotoxemia & 1 & Dezembro/2006 & Córrego das Antas \\
\hline Linfadenite caseosa & 1 & Agosto/2010 & Padre Bernardo ${ }^{2}$ \\
\hline Toxemia da prenhez & 1 & Junho/2006 & Recanto das Emas \\
\hline Esteatonecrose & 1 & Agosto/2009 & São Sebastião \\
\hline Calcinose enzoótica & 1 & Abril/2009 & Planaltina-DF \\
\hline Verminose & 1 & Outubro/2008 & Fercal \\
\hline Inconclusivo & 1 & Março/2007 & Vargem Bonita ${ }^{1}$ \\
\hline
\end{tabular}

n= número de casos; *= provável participação do Oestrus ovis na morte do animal; números sobrescrito iguais designam propriedades iguais. 
Tabela 5: Número de pequenos ruminantes diagnosticados com Oestus ovis durante a necropsia por ano e espécie parasitada, durante o período de 2003 a 2012 no Distrito Federal e Entorno.

\begin{tabular}{|c|c|c|}
\hline \multirow{2}{*}{ Ano } & \multicolumn{2}{|c|}{ Espécie } \\
\hline & Ovino & Caprino \\
\hline 2003 & - & - \\
\hline 2004 & 1 & - \\
\hline 2005 & - & - \\
\hline 2006 & 1 & 1 \\
\hline 2007 & 6 & - \\
\hline 2008 & 4 & - \\
\hline 2009 & 4 & 2 \\
\hline 2010 & 1 & - \\
\hline 2011 & 1 & - \\
\hline 2012 & 1 & - \\
\hline TOTAL & 19 & 3 \\
\hline
\end{tabular}




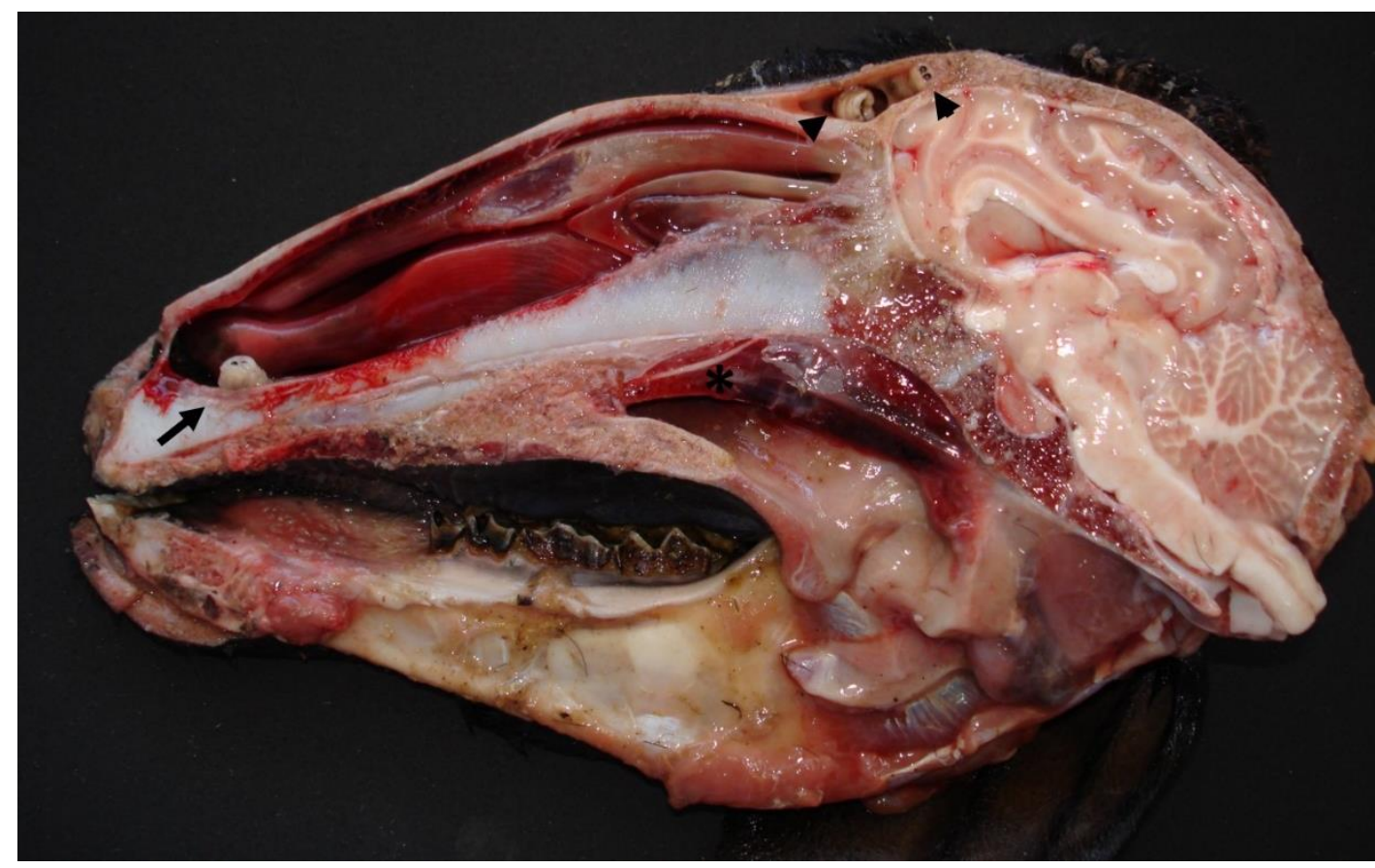

Figura 4: Ovino: Heme cabeça. Presença de larvas de Oestrus ovis em cavidade nasal (seta) e seios nasais (cabeça de seta). Há moderada a acentuada hiperemia de conchas nasais e coanas (asterisco).

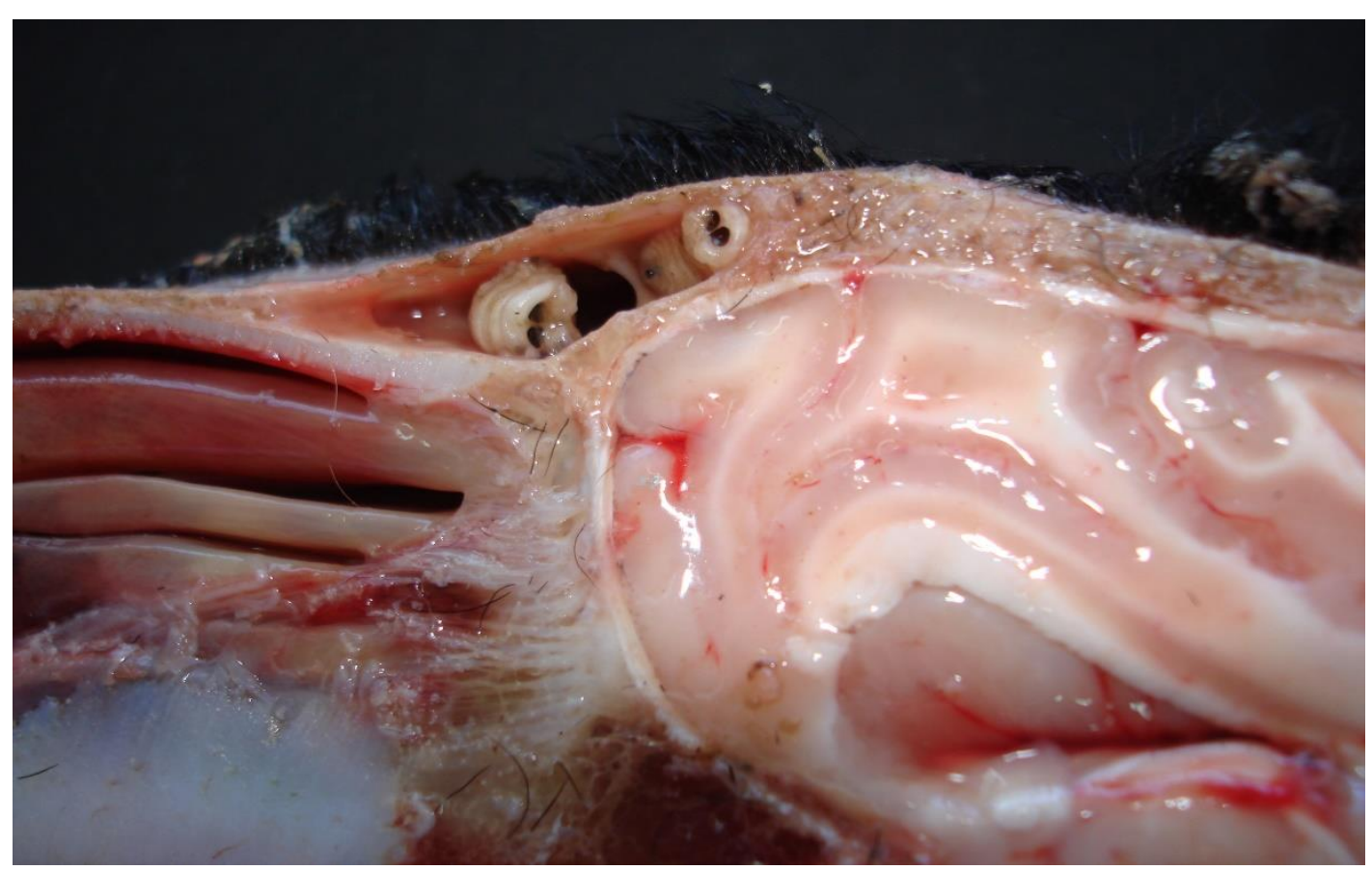

Figura 5: Ovino: Heme cabeça. Presença de duas larvas de Oestrus ovis em seios nasais. É possível observar os espiráculos da larva (área enegrecida). 


\section{5 - DISCUSSÃO}

A suspeita de pitiose rinofacial e conidiobolomicose foi baseado na apresentação clínica, com aumento de volume rostral ou exoftalmia, associado a dificuldade respiratória e pastejo em áreas alagadas com matéria orgânica vegetal nas proximidades. O diagnóstico foi confirmado utilizando PCR nos casos de conidiobolomicose e imuno-histoquímica nos casos de pitiose rinofacial.

As rinites micóticas e oomicóticas relatadas ocorreram no período das chuvas (janeiro e fevereiro) ou imediatamente após seu término (maio). A maioria dos surtos de pitiose e conidiobolomicose relatados no Brasil também ocorrem durante ou logo após a estação das chuvas, principalmente durante os meses com alta temperatura e umidade do ar (Leal et. al. 2001a, Santurio et. al. 2006, Boabaid et. al. 2010, Furlan et. al 2010, Portela et. al. 2010, Aguiar et. al. 2014). A ocorrência de casos mesmo após o período de chuvas é atribuída à presença de áreas que permaneçam alagadas por longos períodos mesmo durante a seca. Tanto o $P$. insidiosum quanto o Conidiobolus spp. proliferam em matéria orgânica vegetal em decomposição próximo a áreas alagadiças, onde a umidade é maior e essa proliferação é mais intensa (Leal et. al. 2001a, Santurio et. al. 2006, Boabaid et. al. 2010). Na seca a forragem permanece mais verde ao redor das áreas mais úmidas, favorecendo proliferação desses agentes, há um aumento da pressão de pastejo nessa área devido melhor qualidade das forrageiras, causando consequentemente um aumento de exposição dos animais ao fungo e oomiceto (Aguiar et. al. 2014).

Em todas as propriedades desse estudo onde ocorreram as rinites micóticas ou oomicóticas existiam áreas alagadiças, com vegetação circundante onde os animais bebiam água e pastejavam nas margens. Os surtos de conidiobolomicose e pitiose em animais estão sempre associados ao contato com matéria orgânica vegetal presente na água (Tabosa et. al. 2004, Riet-Correa et. al. 2008, Saturnino et. al. 2008, Portela et. al. 2010, Carrera et. al. 2013, Aguiar et. al. 2014). A presença de áreas alagadas, vegetação abundante e temperatura ambiental superior a $20^{\circ} \mathrm{C}$ propiciam condições ideais para a reprodução dos fungos e oomicetos. O pastejo ao redor de açudes, presença de matéria vegetal abundante e pressão de pastejo são fatores de risco para ocorrência das rinites micóticas e oomicóticas (Aguiar et. al. 2014).

A área de resteva de arroz, onde foram observados os surtos de conidiobolomicose, é extremamente propícia para a proliferação desses agentes. Na mesma 
propriedade os equinos já haviam apresentado lesão cutânea granulomatosa, que foi associado ao Pythium insidiosum após resposta ao tratamento. É comum a ocorrência de pitiose cutânea em equinos nessas condições epidemiológicas (Leal et. al. 2001a b, Sallis et. al. 2003, Headley \& Junior 2004, Biava et. al. 2007). Um surto de conidiobolomicose foi descrito em uma área irrigada de plantação de cocos, onde havia ambiente propício semelhante para a proliferação fúngica (Riet-Correa et. al 2008).

O uso de resteva para alimentação de ruminantes é comum entre os produtores dessa região. A integração lavoura-pecuária está sendo muito utilizada para se obter uma melhor exploração do solo, adequação ambiental e maior viabilidade econômica. A consorciação de pastagens juntamente com a lavoura de grão proporciona oferta de forragem em quantidade e qualidade superiores as normalmente observadas principalmente durante o período da seca, diminuindo a perda de rendimento dos animais (Alvarenga, 2004, Guimarães Júnior et. al. 2010), porém o uso da resteva de arroz, devido suas características de cultivo em áreas alagadas, pode favorecer a ocorrência de surtos de conidiobolomicose, pitiose ou outras doenças fúngicas nos animais.

Evitar o acesso dos animais as áreas alagáveis ou remover a matéria orgânica que circunda essas áreas é uma forma de diminuir a infecção dos animais (Tabosa et. al. 2004, Aguiar et. al. 2014). Diminuir a pressão de pastejo ou o tempo de acesso dos animais as áreas alagadas também pode contribuir para diminuição no número de casos (Aguiar et. al. 2014).

Foram observados dois surtos de pitiose rinofacial e dois surtos de conidiobolomicose durante o período estudado, sugerindo que ambas apresentem importância semelhante na região de atuação do LPV-UnB. A morbidade dessas duas enfermidades foi semelhante, porém a letalidade da conidiobolomicose foi de $100 \%$, enquanto esse índice na pitiose rinofacial foi de $75 \%$.

$\mathrm{Na}$ região semiárida da Paraíba e Rio Grande do Norte os surtos de conidiobolomicose são mais frequentes e a pitiose rinofacial ocorre apenas em casos isolados e geralmente associados aos focos da rinite por Conidiobolus spp. (Portela et. al. 2010, Aguiar et. al. 2014). Essa diferença de ocorrência entre as duas enfermidades não foi notada nesse estudo, sugerindo que ambas tem ocorrência similar e a importância deve ser diferenciada pela maior letalidade da conidiobolomicose.

A pitiose em ovinos foi descrita pela primeira vez no Brasil em 2004 (Tabosa et. al. 2004). Foram observados dois surtos no estado da Paraíba, onde a manifestação clínica consistia de dermatite granulomatosa semelhante ao quadro observado comumente em equinos e raramente em bovinos (Leal et. al. 2001a, Sallis et. al. 2003, Headley et. al 2004, Tabosa et. 
al 2004, Gabriel et. al. 2008, Galiza et. al. 2014). Durante a necropsia desses ovinos foi observada lesão granulomatosa no pulmão além das lesões dérmicas (Tabosa et. al. 2004).

Pythium insidiosum causando rinite em ovinos no Brasil foi descrito em Mato Grosso, Paraíba, Pernambuco e Bahia (Santurio et. al 2008, Riet-Correa et. al 2008, Portela et. al 2010, Carrera et. al. 2013). Não haviam relatos anteriores na região do Distrito Federal. O aumento de volume nasal com deformidade da face, edema na junção mucocutânea nasal e do lábio superior associado com dispneia e secreção nasal observado nos animais desse estudo é semelhante ao quadro clínico observado em outros surtos de pitiose no Brasil (Riet-Correa et. al 2008, Santurio et. al 2008, Carrera et. al. 2013, Aguiar et. al. 2014). Apesar desse oomiceto poder causar o quadro rinofaríngeo a frequência da apresentação rinofacial é muito superior, podendo a apresentação clínica ser utilizada como base para diagnóstico diferencial entre pitiose e conidiobolomicose em locais onde o PCR ou IHQ não estão disponíveis (Ubiali et. al. 2013).

A evolução clínica da pitiose rinofacial é extremamente variável, variando de 13 a 180 dias nos ovinos avaliados, apresentando essa evolução mais longa em um animal submetido ao tratamento. Outros autores relatam evolução clínica de 14 a 50 dias (Riet-Correa et. al. 2008, Saturnino et. al. 2008). A pitiose cutânea em equinos também apresenta evolução variável, sendo descrita evolução de dias a vários meses, e alguns animais podem desenvolver uma forma atípica com curso clínico superior há um ano. Acredita-se que nessa espécie o curso clínico esteja associada a eficiência do sistema imune, mesmo que o animal não consiga eliminar o agente é possível isolar a área afetada evitando o quadro de evolução progressiva, coma e morte (Leal et. al. 2001b, Sallis et. al. 2003). A evolução clínica pode estar diretamente relacionada ao sistema imune, ao estabelecimento de tratamento eficaz ou a própria característica do agente, que diferentemente dos fungos contém celulose e b-glucanos na sua parede, que ativa um padrão de resposta pouco eficaz e dificulta a ação de medicamento sobre o agente.

Nos animais desse estudo durante a necropsia foi observada proliferação de tecido friável na cavidade nasal, friável e fétido. O mesmo achado é descrito por outros autores (Riet-Correa et. al. 2008, Saturnino et. al. 2008, Portela et. al. 2010, Carrera et. al. 2013, Ubiali et. al. 2013, Aguiar et. al. 2014). Nos casos de pitiose rinofacial também é descrito osteólise no palato duro, fístulas oronasais, comprometimento de glândulas parótidas, linfonodos submandibulares e pulmão (Riet-Correa et. al. 2008, Saturnino et. al. 2008, Portela et. al. 2010, Carrera et. al. 2013, Ubiali et. al. 2013). Nesse estudo, o comprometimento de glândula, 
linfonodos e pulmão também foi evidenciado, porém as fístulas oronasais ou áreas de osteólise não foram observadas nos animais.

Na microscopia, a presença áreas necróticas em quantidade variável circundadas por quantidade moderada a acentuada de polimorfonucleares, presença de imagens negativas compatíveis com hifas fúngicas e reação escassa ou moderada de Splendore-Hoeppli reforçaram a suspeita de pitiose rinofacial. Ao redor do infiltrado de polimorfonucleares notavase quantidade acentuada de macrófagos com quantidade geralmente escassa de células gigantes multinucleadas, caracterizando o granuloma. O aspecto microscópico é compatível com o observado anteriormente em surtos de pitiose rinofacial (Riet-Correa et. al. 2008, Saturnino et. al. 2008, Portela et. al. 2010, Carrera et. al. 2013, Ubiali et. al. 2013).

A conidiobolomicose causando rinite em ovinos foi anteriormente descrita nos estados do Piauí, Paraíba, Mato Grosso, Rio Grande do Sul, Santa Catarina, Rio Grande do Norte, Pernambuco, Ceará (Silva et. al. 2007b, Boabaid et. al. 2008, Riet-Correa et. al 2008, Pedroso et. al. 2009, Furlan et. al. 2010, Portela et. al. 2010, Silva et. al 2010, Câmara et. al. 2011, Mendonça et. al. 2012), e o presente trabalho descreve pela primeira vez a doença no estado de Goiás.

A morbidade encontrada variou de 4,3\% a 7,4\%, em outros estudos a morbidade observada variou de 0,66\% a 73,3\% (Silva et. al. 2007a, Boabaid et. al. 2008, Riet-Correa et. al 2008, Pedroso et. al. 2009, Furlan et. al. 2010, Portela et. al. 2010, Silva et. al 2010, Câmara et. al. 2011, Mendonça et. al. 2012, Aguiar et. al. 2014). A conidiobolomicose não é facilmente adquirida, os animais precisam ser constantemente desafiados para que a infecção ocorra. $\mathrm{O}$ estado imunológico dos ovinos parece não interferir no estabelecimento dessa doença (Aguiar et. al. 2014). A ocorrência de surtos com alta morbidade sugere uma exposição ais intensa ao agente.

A letalidade nesse estudo e em todos os relatos anteriores foi de $100 \%$ (Silva et. al. 2007a, Boabaid et. al. 2008, Riet-Correa et. al 2008, Pedroso et. al. 2009, Furlan et. al. 2010, Portela et. al. 2010, Silva et. al 2010, Câmara et. al. 2011, Mendonça et. al. 2012, Aguiar et. al. 2014). A letalidade alta pode estar associada ao diagnóstico tardio da doença e ineficácia do tratamento. O quadro clínico só é observado quando o comprometimento da cavidade nasal já é significativo, o que dificulta a ação do medicamento e melhora do animal (Riet-Correa et. al. 2008).

Os animais apresentaram evolução clínica de 10 dias nesse estudo. O curso clínico da conidiobolomicose rinofaríngea pode variar de 3 a 180 dias (Silva et. al. 2007a b, Riet-Correa et. al. 2008, Portela et. al. 2010), mas geralmente fica em torno de 7 a 15 dias (Riet- 
Correa et. al. 2008). A cronicidade das lesões histopatológicas sugere que é necessário um tempo maior para o estabelecimento da lesão na cavidade nasal (Riet-Correa et. al. 2008). A evolução clínica pode ser extremamente variável em função da extensão e gravidade da lesão, a tentativa de tratamento e a imunidade do animal também podem interferir no curso clínico.

A exoftalmia associada a dificuldade respiratória, com secreção nasal foi ao achado clínico mais consistente nos animais com conidiobolomicose. A exoftalmia unilateral é descrita como o principal achado da conidiobolomicose, sendo observada em todos animais com rinite rinofaríngea (Ubiali et. al. 2013). O aumento de volume na região nasofaríngea, com exoftalmia ou não, também é um importante sinal clínico (Silva et. al. 2007b, Boabaid et. al. 2008, Riet-Correa et. al 2008, Pedroso et. al. 2009, Furlan et. al. 2010, Portela et. al. 2010, Silva et. al 2010, Câmara et. al. 2011, Mendonça et. al. 2012). Na Paraíba um animal apresentava lesão de palato duro, palato mole, glote e orofaringe, sem acometer a cavidade nasal (Portela et. al. 2010). A conidiobolomicose também pode se apresentar na forma rinofacial, porém com uma frequência infinitamente menor (Ubiali et. al. 2013), por isso a localização das lesões pode ser utilizada como forma de diferenciar essas duas doenças. Em todos os animais do nosso estudo a localização da lesão causada pela conidiobolomicose foi rinofaríngea.

A massa de coloração pálida, consistência friável, com áreas de necrose multifocais, se estendendo do terço médio da cavidade nasal à placa cribriforme do osso etmoide foi o achado de necropsia mais evidente. O comprometimento da região nasofaríngea, com uma massa obstruindo essa região é o achado macroscópico mais descrito na conidiobolomicose (Silva et. al. 2007a, Boabaid et. al. 2008, Riet-Correa et. al. 2008, Saturnino et. al. 2008, Pedroso et. al. 2009, Furlan et. al. 2010, Portela et. al. 2010, Carrera et. al. 2013). Essa lesão tende a invadir a região etmoidal e a placa cribriforme (Ubiali et. al. 2013). A lesão observada na pitiose tende a ser mais friável enquanto a lesão da conidiobolomicose é mais firme (Ubiali et. al. 2013), essa diferença não foi evidenciada no nosso estudo.

A lesão no trato gastrointestinal causada por Conidiobolus lamprauges observada no intestino de um animal, foi semelhante a encontrada no cólon e abomaso de ovinos com a enfermidade (Boabaid et. al. 2008, Portela et. al. 2010). A disseminação da pitiose e da conidiobolomicose para outros órgãos possivelmente ocorreu por via hematógena através da formação de êmbolos.

Microscopicamente o acentuado infiltrado de macrófagos, com quantidade acentuada de células epitelioides e células gigantes multinucleadas, com áreas de necrose, imagens negativas de hifas fúngicas, circundadas por marcada reação de Splendore-Hoeppli foi observado em fragmentos da cavidade nasal, pulmão, língua, linfonodo e intestino delgado. $\mathrm{Na}$ 
conidiobolomicose além do granuloma com áreas multifocais de necrose, também é descrito hiperplasia de fibroblastos, proliferação vascular e reabsorção óssea na região do osso etmoide (Boabaid et. al. 2008, Riet-Correa et. al. 2008Furlan et. al. 2010, Portela et. al. 2010, Câmara et. al. 2011, Mendonça et. al. 2012, Ubiali et. al. 2013, Aguiar et. al. 2014). A reação de Splendore-Hoeppli nos casos de pitiose geralmente é menos intensa e as hifas são mais finas, com paredes limítrofes mais espessas (Riet-Correa et. al. 2008, Aguiar et. al. 2014). Nesse estudo a lesão observada na conidiobolomicose é caracterizada por uma quantidade acentuada de células gigantes multinucleadas enquanto na pitiose essas células estão presentes em menor número. Essa diferença no tipo de célula inflamatória presente na reação também foi observado anteriormente (Ubiali et. al. 2013) e pode ser utilizada como parâmetro para diferenciação microscópica dessas doenças, mesmo que não seja possível a confirmação com métodos mais sensíveis e específicos.

As rinites granulomatosas apresentam baixa incidência em todo Brasil, porém sua alta letalidade e as perdas causadas pela mesma fazem com que essa seja uma doença de importância na medicina veterinária. A falta de diagnóstico precoce e o conhecimento restrito sobre essas doenças dificultam o estabelecimento de medidas preventivas que minimizem a contaminação dos animais.

Oestrus ovis é um parasita economicamente importante da cavidade nasal e dos seios adjacentes em ovinos e caprinos em todo o mundo. Afeta negativamente a saúde de pequenos ruminantes, causando irritação nas vias respiratórias, infecções bacterianas secundárias e perdas econômicas devido à redução na produção de carne e leite (Caracappa et. al. 2000, Dorchies et. al 2000, Murguia et. al. 2000, Tabouret et. al. 2001, Alcaide et al. 2003, Arslan et. al 2009, Shoorijeh et al. 2009).

A ocorrência de oestrose observada nesse estudo foi 4,08\%, similar ao observada em ovinos na Argentina (Trezeguet, 1996). Esse índice pode diferir muito em outras partes do mundo, variando de 13,1\% a 65\% dos animais parasitados (Yilma \& Dorchies 1991, Dorchies et. al 2000, Shoorijeh et. al. 2011). Estudo sorológico em caprinos no sudoeste da Itália determinou positividade em $30 \%$ dos animais em mais de $90 \%$ das propriedades (Alcaide et. al 2005). Em um estudo retrospectivo realizado no Rio Grande do Sul, a ocorrência da parasitose foi de $0,3 \%$ (Rissi et. al. 2010). No acompanhamento de três surtos no Mato Grosso a morbidade observada variou de $69 \%$ a $100 \%$ dos animais (Schenkel et. al. 2012). Na região de Patos, Paraíba, onde há predomínio de rebanho caprino, essa doença não tem sido diagnosticada (Portela et. al 2010). 
A oestrose, por ser uma doença que geralmente não causa a morte dos animais não é frequentemente diagnosticada nos laboratórios de patologia (Portela et. al. 2010). O tratamento prévio pelos proprietários e consequente eliminação das larvas pode diminuir a observação das mesmas na necropsia. Além disso, abertura da cavidade nasal pode não ter sido realizada de maneira sistemática, uma vez que material oriundo de necropsias externas também foram analisados e muitas vezes os laudos dessas necropsias não estavam completamente preenchidos. Provavelmente, a ocorrência dessa parasitose é maior do que o descrito nesse estudo e as perdas causadas por essa parasitose devem ser mais significativas.

Mesmo assim, é possível observar um aumento de quase três vezes no número de casos de Oestrus ovis diagnosticados em pequenos ruminantes na região do DF e entorno. Até 2006 a prevalência estimada da parasitose era 1,42\% (Borges et. al. 2007), e atualmente a ocorrência aumentou para 4,08\%. O crescimento no tamanho dos rebanhos ou maior densidade de animais aumenta a chance de infestação ou reinfestação pelo parasita (Alcaide et. al. 2005). Do ano de 2006 até 2009, houve um aumento de 14,26\% no rebanho ovino da região do Distrito Federal, com manutenção do rebanho caprino (IBGE, 2009). Se esse aumento do rebanho persistir é esperado que nos próximos anos haja um incremento significativo da ocorrência da oestrose nessa região.

O parasitismo foi detectado durante quase todos os meses do ano, com uma maior concentração de casos no período da seca. Larvas de Oestrus ovis podem parasitar a cavidade nasal de ovelhas durante todo o ano, com aumento do estágio larval L1 nos meses de maior precipitação pluviométrica e pequenas quantidades de larvas L3 durante todo o período (Scala et. al. 2001). No Planalto Catarinense as larvas de O. ovis são observadas parasitando os animais com maior frequência na primavera e verão, quando as temperaturas variaram entre $12^{\circ} \mathrm{C}$ e $20^{\circ} \mathrm{C}$, com tendência de aumento da umidade (Ramos et. al. 2006). No Mato Grosso foram relatados surtos nos meses de abril e maio (Schenkel et. al. 2012). As larvas de oestrus conseguem se adaptar as condições climáticas do local, apesar de se desenvolverem com maior facilidade em regiões quentes e secas (Alcaide et. al. 2005). Na região desse estudo as temperaturas médias se mantém acima dos $18^{\circ} \mathrm{C}$ durante todo ano, o que favorece o desenvolvimento da larva. Nos meses de menor índice pluviométrico médio, foi encontrado o maior número de animais parasitados. No mês de julho, apesar de não terem sido detectados casos de oestrose, as condições climáticas eram favoráveis, e possivelmente haviam animais parasitados porém que não foram diagnosticados na necropsia. Nos meses de maior índice pluviométrico e umidade elevada, houve número menor de animais parasitados, podendo ser esse um fator limitante para a ocorrência da doença. 
É importante determinar com clareza qual a época de maior ocorrência dessa parasitose, para que o produtor possa estabelecer medidas preventivas, como uso de parasiticida de efeito residual e prolongado, anterior ao período de deposição das larvas. Com essas medidas seria possível minimizar a parasitose e as perdas causadas por ela.

No Distrito Federal, a maioria dos animais com oestrose eram adultos. A ocorrência da doença geralmente é maior em animais adultos (Gabaj et. al. 1993, Dorchies et. al. 2000, Caracappa et. al. 2000, Scala et. al. 2001, Alcaide et. al. 2003, Arslan et. al. 2009, Shoorijeh et. al. 2011, Attindehou et. al. 2012). Esse parasita estimula o sistema imune e a produção de anticorpos, o fato de animais adultos serem os mais parasitados sugere que a imunidade adquirida contra o parasita é falha (Murguía et. al. 2000, Angulo-Valadez et. al. 2009).

A maior parte dos ovinos avaliados era da raça santa inês e apresentavam pelagem escura. Os animais de focinho preto tem uma maior probabilidade de adquirir a oestrose quando comparados com os animais de focinho manchado ou claro (Murguía et. al. 2000, Arslan et. al. 2009). Acredita-se que a atração da mosca adulta pela narina escura está interligada a conservação da temperatura, mantendo a temperatura ideal para o desenvolvimento do parasita (Murguía et. al. 2000). Não é possível fazer uma associação com a raça, pois ovinos santa inês ou mestiços dessa raça são os mais comumente criados nessa região.

O número de larvas por animal parasitado no DF e Entorno apresentou variação considerável, sendo encontrada de 2 a 15 larvas por animal. Esse dado não estava descrito em todas as fichas de necropsia. Sabe-se que a variação na quantidade de larvas por animal pode ser enorme, com 24 a 94 larvas por animal em altas infestações, apesar de rebanhos apresentarem números médios de 9,4 parasitas/animal (Gabaj et. al. 1993, Caracappa et. al 2000, Ramos et. al 2006).

A taxa de estabelecimento das larvas é baixa $(11,2 \%)$, tendendo a aumentar quando ocorrem repetidas deposições de larvas no mesmo animal (Tabouret et. al 2003). Animais imunossuprimidos apresentam maiores taxas de estabelecimento e crescimento das larvas, demonstrando que a resposta imune do hospedeiro tem um papel importante no controle da população de Oestrus ovis (Jacquiet et. al. 2005). A quantidade de larvas está diretamente relacionada com a gravidade do quadro clínico. Pois além da lesão mecânica causada pelos espinhos nas cutículas das larvas, essas produzem enzimas que lesam diretamente a mucosa nasal. Animais pouco parasitados podem não apresentar sintomatologia, como ocorreu na maioria dos animais no DF e Entorno, o que dificulta o diagnóstico. 
Os animais avaliados apresentaram larvas instaladas predominantemente em seios nasais e paranasais e conchas nasais. Os parasitas encontrados na traqueia, possivelmente migraram para o local após a morte do animal. Na oestrose, as larvas são encontradas com frequência nos seios frontais, cavidade nasal e meato nasal (Ylma \& Dorchies 1991, Gabaj et. al 1993, Arslan et. al. 2009). Oestrus ovis não tem característica de se manter aglomerado como outras miíases, provavelmente no intuito de diminuir a reação inflamatória local, podendo permanecer no hospedeiro por mais tempo (Lutz, 1917).

Os animais desse estudo apresentaram sinais clínicos característicos da oestrose como apatia, secreção nasal, dispneia e emagrecimento. Esses sinais clínicos são similares ao observado em outros estudos (Dorchies, 1997, Scala et. al. 2001, Alcaide et. al 2005, Jacquiet et. al. 2005, Angulo-Valadez et. al. 2009, Alem et. al. 2010, Angulo-Valadez et. al. 2011, Schenkel et. al. 2012). Os espirros e secreção nasal são considerados os sinais clínicos mais prevalentes na oestrose. No nosso estudo apenas um animal apresentou espirro. Em alguns casos, pode ocorrer obstrução das vias aéreas, interferindo na alimentação e tempo de ruminação, gerando déficit nutricional e diminuição na produção (Alcaide et. al. 2005, AnguloValadez et. al. 2011). O animal também pode apresentar apatia, tosse, ataxia, epistaxe, incoordenação motora, meneios de cabeça e pressão da cabeça contra objetos (Dorchies, 1997, Alcaide et. al. 2005, Schenkel et. al. 2012).

Alguns ovinos e caprinos não apresentam sinais clínicos, mesmo com a presença do parasita na cavidade nasal. Em contraste, alguns indivíduos apresentam sinais clínicos severos mesmo com poucas larvas de Oestrus ovis. A ausência de sinais clínicos no hospedeiro pode caracterizar uma imuno tolerância do animal ao parasita, no intuito de diminuir os danos causados, demonstrando uma melhor relação hospedeiro-parasita. Já a presença de sinais clínicos graves em animais com poucas ou nenhuma larva pode ocorrer pois a lesão persiste mesmo após as larvas abandonarem o hospedeiro (Jacquiet et. al. 2005).

Esses achados contraditórios quanto a resposta imune do hospedeiro sugerem que exista uma variação genética que determine resistência e susceptibilidade das ovelhas a oestrose (Angulo-Valadez et. al. 2008) e que uma variação genética ou antigênica das larvas possa influenciar a manifestação clínica nos hospedeiros (Grisez-Duranton et. al. 2002, AnguloValadez et. al 2011).

Além disso, o desenvolvimento do parasita em um hospedeiro não específico gera uma resposta inflamatória mais exacerbada do hospedeiro, o que reflete sinais clínicos mais graves e um aumento de ocorrência, pela maior facilidade de detectar a doença. $O$ fato dos caprinos apresentarem menor taxa de parasitismo, com evolução mais rápida da larva e sinais 
clínicos mais brandos pode sugerir que a mosca de Oestrus ovis se adaptou posteriormente aos ovinos e por isso nesses animais os sinais clínicos são mais exacerbados, devendo ocorrer novos estudos para elucidar a relação hospedeiro-parasita nesses dois hospedeiros (Dorchies et. al. 2000).

Nos animais do DF e Entorno as principais alterações macroscópicas associadas a oestrose envolviam lesões no trato respiratório superior, com presença de sinusite, hiperemia de conchas nasais e coanas e secreção nasal. As rinites e sinusites são achados frequentes nos animais parasitados (Tabouret et. al. 2003, Alem et. al. 2010, Angulo-Valadez et. al. 2011). Presença de secreção nasal mucoide, purulenta ou piohemorrágica também são descritas (Tabouret et. al. 2003, Angulo-Valadez et. al. 2009, Alem et. al. 2010). As lesões são geralmente mais severas em animais que apresentam seis ou mais larvas na cavidade nasal (Angulo-Valadez et. al. 2009) e imediatamente após o desenvolvimento da larva para L2 e L3 (Angulo-Valadez et. al. 2011). A confirmação do diagnóstico deve ser baseada na presença da larva, e devido a tratamento prévio ou ao próprio ciclo do parasita nem sempre a larva é encontrada na cavidade nasal, a presença da hiperemia de conchas nasais e coanas em diversos animais, associada ao quadro clínico pode ser um indicativo dessa doença, sugerindo tratamento no rebanho.

No presente estudo, a oestrose foi um achado incidental de necropsia na maioria dos casos. A parasitose pode estar associada com a causa da morte em dois animais que apresentavam quadro de rinite e sinusite acentuadas, podendo ter contribuído diretamente para morte do animal ou precipitado a mesma agravando o quadro de outras doenças. A oestrose não é uma importante causa de morte nos animais. Porém pode ocorrer concomitantemente com outras doenças, causando altos índices de mortalidade (Schenkel et. al. 2012).

A principal causa de morte dos animais com oestrose nesse estudo está associada com alterações pulmonares, pneumonias e broncopneumonias $(n=627,27 \%)$, hemoncose $(n=5$ $22,72 \%)$ e desnutrição (n=3 13,64\%). É difícil determinar o quanto a oestrose pode ter influenciado nesses quadros, uma vez que faltam dados sobre evolução do quadro clínico e acompanhamento do rebanho.

Nos últimos anos, a oestrose em caprinos e ovinos que era praticamente desconhecida na região Centro-Oeste, tem apresentado um aumento significativo. Isso, em parte, ocorreu devido à expansão da ovinocultura regional e com a importação de animais de outras regiões do Brasil onde a doença tem alta prevalência. 


\section{6-CONCLUSÕES}

As rinites são doenças que causam prejuízos econômicos na produção de animais, seja pela morte do animal seja pela diminuição na produção. O conhecimento das possíveis causas de rinite em determinada região é importante para aprimorar o diagnóstico, instituindo o tratamento adequado ou medidas profiláticas que minimizem as perdas.

No DF e Entorno, a conidiobolomicose e a pitiose rinofacial são doenças pouco conhecidas e ainda não haviam sido descritas, o pouco conhecimento sobre as características epidemiológicas dessas doenças dificultava o diagnóstico e o emprego de medidas preventivas. O uso de açudes, cacimbas ou áreas alagadas com matéria orgânica vegetal na borda é essencial para o surgimento da doença. Evitar o contato dos animais com essas áreas ou diminuir a quantidade de matéria verde ao redor são fatores que contribuem para o controle da doença.

Os sinais clínicos, a localização da lesão e a epidemiologia das doenças são fatores que auxiliam no diagnóstico diferencial da conidiobolomicose e pitiose rinofacial. As lesões histopatológicas muito semelhantes podem dificultar a identificação do agente etiológico envolvido, sendo muitas vezes importante a realização de testes auxiliares mais sensíveis.

Por serem de difícil tratamento, o controle é a melhor forma de minimizar as perdas causada pelas rinites granulomatosas nos rebanhos ovinos.

A baixa prevalência da oestrose observada nesse estudo pode estar subestimada, pois essa doença geralmente não causa a morte dos animais e os proprietários tendem a tratar animais com os sinais clínicos característicos, dificultando o diagnóstico post mortem baseado na observação das larvas. Mesmo assim, as perdas causadas por essa miíase não podem ser desconsideradas. E deve se ressaltar que ocorreu um aumento da oestrose em caprinos e ovinos na região nos últimos anos.

A distribuição dessa doença é ampla na região e com potencial para expandir para outros rebanhos. As condições climáticas podem favorecer o desenvolvimento desse parasita e associado ao aumento da criação intensiva de ovinos e caprinos, podem gerar um ambiente ideal para aumento da ocorrência dessa parasitose com perdas significativas da produção.

A maior ocorrência de oestrose no período da seca pode sugerir tratamentos prévios com antiparasitários de ação residual prolongada, diminuindo o estabelecimento das larvas e consequentemente os prejuízos. É importante que novos estudos averiguem se esse é o real período de maior ocorrência dessa parasitose. 
Esse trabalho vem para corroborar com as informações observadas em outras regiões do Brasil, demonstrando similaridade nos aspectos clínicos e anatomopatológicos, e alerta para importância da rinite micótico, oomicótica e parasitária no DF e Entorno.

\section{AGRADECIMENTOS}

À professora doutora Glaucia Denise Kommers pela realização da imunohistoquímica e ao Laboratório de Microbiologia Veterinária e Biologia Molecular Veterinária da Universidade Federal de Mato Grosso, professor doutor Luciano Nakazato e professora doutora Valéria Dutra pela realização da PCR. 


\section{7- REFERÊNCIAS BIBLIOGRÁFICAS}

ABO-SHEHADA, M.N. ET AL. Oestrus ovis larval myiasis among goats in northern Jordan. Preventive Veterinary Medicine, v.59, p.13-19, 2003.

AGUIAR, G.M.N., SIMÕES, S.V.D., SANTOS, S.A., MARQUES, A.L.A., SILVA, T.R., DANTAS, A.F.M., RIET-CORREA, F. Aspectos epidemiológicos da conidiobolomicose em ovinos na região semiárida do Nordeste do Brasil. Ciência rural. no prelo, 2014.

ALCAIDE, M., REINA, D., SÁNCHEZ, J., FRONTERA, E., NAVARRETE, I. Seasonal variations in the larval burden distribution of Oestrus ovis in sheep in the southwest of Spain. Vet. Parasitol. v.118, p.235-241, 2003.

ALCAIDE, M., REINA, D., FRONTERA, E., NAVARRETE, I. Epidemiology of Oestrus ovis (Linné, 1761) infestatios in goats in Spain. Vet. Parasitol. v.130, p.277-284, 2005.

ALEM, F., KUMSA, B., DEGEFU, H. Oestrus ovis larval myiasis among sheep and goats in Central Oromia, Ethiopia. Trop. Anim. Health. Prod. v.42, p.697-703, 2010.

ALVARENGA, R.C. Integração lavoura-pecuária. In: Simpósio de pecuária de corte 3. Belo Horizonte, Minas Gerais. 2004. Anais. CD-ROM.

ANGUlO-VAlADEZ, C.E., SCALA, A., GRISEZ, C., PREVOT, F., BERGEAUD, J.P., CARTA, A., CEPEDA-PAlaCIOS, R., ASCENCIO, F., TEREFE, G., DORCHIES, P., JACQUIET, P. Specific IgG antibody responses in Oestrus ovis L. (Diptera: Oestridae) infected sheep: associations with intensity of infection and larval development, Vet. Parasitol. v.155, p.257-263, 2008.

ANGUlO-VAlADEZ, C.E., CEPEDA-PALACIOS, R., ASCENCIO F., JACQUIET P., DORCHIES, P., RAMÍREZ-ORDUÑA, J.M. Relationships of systemic IgG antibody response and lesions caused by Oestrus ovis L. larvae (Diptera: Oestridae) in infected goats. Rev. eléctron. vet. v.10, n.11, 2009.

ANGUlO-VAlADEZ, C.E., ASCENCIO F., JACQUIET P., DORCHIES, P., CEPEDAPALACIOS, R. Sheep and goat imune responses to nose bot infestation: a review. Medical and Veterinary Entomology, v.25, p.117-125, 2011.

ARSLAN, M.O., KARA, M., GICIK, Y. Epidemiology of Oestrus ovis infestation in sheep in Kars province of north-eastern Turkey. Tropical Animal Health And Production. v.41, p.299-305, 2009.

ATTINDEHOU, S., SALIFOU, S., GBANGBOCHE, A.B., ABIOLA, F.A. Prevalence of the small ruminant's oestrosis in Benin. j. Anim. Vet, Adv. v.11, n.10, p.1647-1650, 2012. 
BIAVA, J.S., OLLHOFF, D.R., GONÇALVES, R.C., BIONDO, A.W. Zigomicose em equinosrevisão. Rev. Acad. v.5, n.3, p.225-230, 2007.

BIU, A.A., NWOSU, C.O. Incidence of Oestrus ovis infestation in Borno-White Sahel goats in the semi-arid zone of Nigeria. Vet. Res. v.30, p.109-112, 1999.

BOABAID, F.M., FERREIRA, E.V., ARRUDA, L.P., GASPARETTO, N.D., SOUZA, R.L., SILVA, M.C., DUTRA V., NAKAZATO, L., COLODEL, E.M. Conidiobolomicose em ovinos no Estado de Mato Grosso. Pesq. Vet. Bras. v.28, n.1, p.77-81, 2008.

BORGES, J.R., MOSCARDINI, A.R.C., TEIXEIRA NETO, A.R., MEIRELLES, F., FERREIRA II, R., GOUVÊA, L.V., GODOY, R.F., PALUDO, G.R., REIS JÚNIOR, J., RIBEIRO, L., PEREIRA, C.S., ENEIAS, A.C., FONSECA, E.F., PERECMANIS, S., GUEDES, K.M.R., PITOMBO, C.A. FRANÇA, R.O., RAJÃO, M., CASTRO, M.B. Doenças de ovinos no brasil central: Distrito Federal e Entorno. In: Quinto congresso latinoamericano de especialistas en pequeños ruminantes y camélidos sudamericanos. Memorias. Associación latinoamericana de especialistas en pequeños rumiantes y camélidos sudamericanos. Mendoza, Argentina. 2007. P. 45-47.

CÂMARA, A.C.L., SOTO-BlAnCO, B., BATISTA, J.S., VALE, A.M., FEIJÓ, F.M.C., OLINDA, R.G. Rhinocerebral and rhinopharyngeal conidiobolomycosis in sheep. Ciência Rural. v.41, n.5, p.862-868, 2011.

CANSI, E.R., CASTRO, M.B.C., MUSTAFA, V.S., PORTO, M.R., BORGES, J.R. Ovis aries (Artiodactyla: Bovidae) e Capra hircus (Artiodactyla: Bovidae) parasitados por Oestrus ovis (Diptera: Oestridae) no Distrito Federal, Brasil. EntomoBrasilis. v.4, n.3, p.147-149, 2011.

CARACAPPA, S., RILLI, S., ZANGHI, P., DI MARCO, V., DORCHIES, PH. Epidemiology of ovine oestrosis (Oestrus ovis Linné,1761, Diptera: Oestridae) in Sicily. Vet. Parasitol. v.92, p.233-237, 2000.

CARrERA, M.V., PEIXOTO, R.M., GOUVEIA, G.V., PESSOA, C.R.M., JESUS, F.P.K., SANTURIO, J.M., BOTTON, S.A., COSTA, M.M. Pitiose em ovinos nos estados de Pernambuco e Bahia. Pesq. Vet. Bras. .v.33, n.4, p.476-482, 2013.

CARRIGAN, M.J., SMALL, A.C., PERRY, G.H. Ovine nasal zygomycosis caused by Conidiobolus incongruus. Aust. Vet. J. v.69, n.10, p.237-240, 1992.

DORCHIES, P; ALZIEU, J.P. L'oestrose ovine, revue. Révue de Médicine Vétérinaire. v.148, n.7, p.565-574, 1997.

DORCHIES, P., DURANTO, C., JACQUIET, P. Pathophysiology of Oestrus ovis infection in sheep and goats: a review. Vet. Rec. v. 142, p.487-489, 1998. 
DORCHIES, P., BERGEAUd, J.P., TABOURET, G., DURANTON, C., PREVOT, F., JACQUIET, P. Prevalence and larval burden of oestrus ovis (Linné, 1761) in sheep and goats in northern Mediterranean region of France. Vet. Parasitol. v.88, p.269-273, 2000.

FURLAN, F.H., LUCIOLI, J., VERONEZI, L.O., FONTEQUE, J.H., TRAVERSO, S.D., NAKAZATO, L., GAVA, A. Conidiobolomicose causada por Conidiobolus lamprauges em ovinos no Estado de Santa Catarina. Pesq. Vet. Bras. v.30, n.7, p.529-532, 2010.

GABAJ, M.M., BEESLEY, W.N., AWAN, M.A. Oestrus ovis myiasis in Libyan sheep and goats. Trop. Anim. Health Prod. v.25, p.65-68, 1993.

GABRIEL, A.L., KOMMERS, G.D., TROST, M.E., BARROS, C.L.S., PEREIRA, D.B., SCHWENDLER, S.E., SANTURIO, J.M. Surto de pitiose cutânea em bovinos. Pesq. Vet. Bras. v.28, n.12, p.583-587, 2008.

GALIZA, G.J.N., SILVA, T.M., CAPRIOLI, R.A., BARROS, C.S.L., IRIGOYEN, L.F., FIGHERA, R.A., LOVATO, M., KOMMERS, G.D. Ocorrência de micoses e pitioses em animais doméstico: 230 casos. Pesq. Vet. Bras. v.34, n.3, p.224-232, 2014.

GOUVEIA, A. M. G. Aspectos sanitários da caprino-ovinocultura no Brasil. In: Simpósio internacional de caprinos e ovinos de corte, 2003, João Pessoa. Anais... João Pessoa: EMEPA, 2003. CD-ROM.

GRISEZ-DURANTON, C., DORCHIES, Ph., JOURDANE, P., DURAND, P. Genetic structure of Oestrus ovis populations in sheep and goats. Vet. Parasitol. v.104, p.167-173, 2002.

GUIMARÃES, A.S. Caracterização da caprinovinocultura em Minas Gerias. 2006. 73f. Dissertação (Mestrado: Medicina veterinária preventiva). Escola de veterinária da Universidade Federal de Minas Gerais, Belo Horizonte, 2006.

GUIMARÃES JUNIOR, R., VILELA, L., MARCHÃO, R.L., PULROLNIK, K., MIRANDA, A.A. Massa seca, composição química e proporções de Brachiaria ruziziensis e de resteva de milho em área de integração lavoura-pecuária (iLP) no Oeste-Baiano. Boletim de pesquisa e desenvolvimento. 1. ed. Embrapa cerrados. 2010. ISSN 1676-918X

HEADLEY, S.A., JUNIOR, H.N.A. Equine cutaneous pythiosis: a report of four cases. Ciência Rural. v.34, n.1, p.289-292, 2004.

IBGE - Instituto Brasileiro de Geografia e Estatística. Diretoria de Pesquisas, Coordenação de Agropecuária, Pesquisa da Pecuária Municipal 2009. Disponível em: <http://www.ibge.gov.br> acesso em 04 de novembro de 2014.

INMET - Instituto Nacional de Meteorologia. Disponível em: < http://www.inmet.gov.br/> acesso em 10 de novembro de 2014. 
JACQUIET P., NGOC T.T.T., NOUVEL X., PRÉVOT F., GRISEZ C., YACOB H.T., BERGEAUD J.P., HOSTE H., DORCHIES P., TABOURET G. Regulation of Oestrus ovis (Diptera: Oestridae) populations in previously exposed and naïve sheep. Vet. Immunol. Immunopathol. v.105, p.95-103, 2005.

LEAL, A.B.M., LEAL, A.T., SANTURIO, J.M., KOMMERS, G.D., CATTO, J.B. Pitiose equina no pantanal brasileiro: Aspectos clínicos-patológicos de casos típicos e atípicos. Pesq. Vet. Bras. v.21, n.4, p.151-156, 2001a.

LEAL, A.T., LEAL, A.B.M., FLORES, E.F., SANTURIO, J.M. Pitiose: revisão bibliográfica. Ciência Rural. v.31, n.4, p.735-743. 2001b.

LUTZ, ADOLPHO. Contribuições ao conhecimento dos Oestrideos brazileiros. Memórias Do Instituto Oswaldo Cruz. v.9, n.1, p.94-113, 1917.

MENDONÇA, F.S., ALBUQUERQUE, R.F., EVÊNCIO-NETO, J., DÓRIA, R.G.S., CAMARGO, L.M., FREITAS, S.H. Conidiobolomycosis in sheep in the state of Pernambuco. Ver. Bras. Med. Vet. v.34, n.3, p.241-246, 2012.

MENDOZA, L., AJELLO, L., McGINNIS, M.R. Infections caused by the oomycetous pathogen Pythium insidiosum. J. Mycol. Med. v.6, n.4, p.151- 164, 1996.

MILLER, R.I., CAMPBELL, R.S.F. Clinical observations on equine phycomycosis. Aust. Vet. J. V.58, p.221-226, 1982.

MORAES, M.A.P., ARNAUD, M.V.C., ALMEIDA, M.M.R. Zigomicose nasofacial no estado do Pará: registro de dois casos. Revista da Sociedade Brasileira de Medicina Tropical. v.30, n.4, p.329-331, 1997.

MORRIS, M., NGELEKA, M., ADOGWA, A.O., LALLA, G., ST-GERMAIN, G., HIGGINS, R. Rhinocerebral zygomycosis in a sheep. Can. Vet. J. v.42, p.227-228. 2001.

MURGUÍA, M.L., RODRÍGUEZ, J.C., TORRES, F.J., SEGURA, J.C. Detection of oestrus ovis and associated risk factors in sheep from the central region of Yucatan, Mexico. Vet. Parasitol. v. 88, p.73-78, 2000.

PAMPIGLIONE, S., GIANNETTO, S., VIRGA, A. Persistence of human myiasis by Oestrus ovis L. (Diptera: Oestridæ) among shepherds of the Etnean area (Sicily) for over 150 years. Parasitologia. v.39, p.415-418, 1997.

PEDROSO, P.M.O., DALTO, A.G.C., RAYMUNDO, D.L., BEZERRA JÚNIOR, P.S., BANDARA, P.M., OLIVEIRA, E.C., SONNE, L., DRIEMEIER, D. Rinite micótica nasofaríngea em um ovino Texel no Rio Grande do Sul. Acta. Scient. Vet. v.37, n.2, p.181$185,2009$. 
PINHEIRO, R.R., GOUVEIA, A.M.G., ALVES, F.S.F., HADDAD, J.P.A. Aspectos epidemiológicos da caprinocultura cearense. Arq. Bras. Med. Vet. Zootec. v.52, n.5, 2000. PORTELA, R.A., RIET-CORREA, F., JÚNIOR, F.G., DANTAS, A.F.M., SIMÕES, A.V.D., SILVA, S.M.S. Doenças da cavidade nasal em ruminantes no Brasil. Pesq. Vet. Bras. v.30, n.10, p.844-854, 2010.

RAMOS, C. I.; BELLATO, V.; SOUZA, A. P.; AVILA, V. S.; COUTINHO, G. C.; DALAGNOL, C. A. Epidemiologia de Oestrus ovis (Diptera: Oestridae) em ovinos no Planalto Catarinense. Ciência Rural. v.36, p.173-178, 2006.

RIBEIRO, V.L.S., OLIVEIRA, C.M.B., ALVES-BRANCO, F.P.J. Prevalence and monthly variations in larvae of Oestrus ovis (Linnaeus, 1761) in sheep from Bage municipality, Rio Grande do Sul, Brazil. Arq. Bras. Med. Vet. Zoot. v.41, p.211-221, 1990.

RIET-CORREA, F., DANTAS, A.F.M., AZEVEDO, E.O., SIMÕES, S.D.V., SILVA, S.M.M.S.,

VILELA, R., MENDOZA, L. Outbreaks of rhinofacial and rhinopharyngeal zygomycosis in sheep in Paraíba, northeastern Brazil. Pesq. Vet. Bras. v.28, n.1, p.29-35, 2008.

RISSI, D.R., PIEREZAN, F., OLIVEIRA FILHO, J.C., FIGHERA, R.A., IRIGOYEN, L.F., KOMMERS, G.D., BARROS, C.S.L. Doenças de ovinos na região Central do Rio Grande do Sul: 361 casos. Pesq. Vet. Bras. v.30, n.1, p.21-28, 2010.

SALLIS, E.S.V., PEREIRA, D.I.B., RAFFI, M.B. Pitiose cutânea em equinos: 14 casos. Ciência Rural. v.33, n.5, p.899-903, 2003.

SANTURIO, J.M., MONTEIRO, A.B., LEAL, A.T., KOMMERS, G.D., SOUSA, R.S., CATTO, J.B. Cutaneous pythiosis insidiosi in calves from the pantanal region of Brazil. Mycopathologia. v.141, p.123-125, 1998.

SANTURIO J.M., ALVES S.H., PEREIRA D.B., ARGENTA J.S. Pitiose: uma micose emergente. Acta Scient. Vet. v.34, n.1, p.1-14, 2006.

SANTURIO, J.M., ARGENTA, J.S., SCHWENDLER, S.E., CAVALHEIRO, A.S., PEREIRA, D.I.B., ZANETE, R.A., ALVES, S.H., DUTRA, V., SILVA, M.C., ARRUDA, L.P., NAKAZATO, L., COLODEL, E.M. Granulomatous rhinitis associated with Pythium insidiosum infection in sheep. Vet. Rec. v.163, n.1, p.276-77. 2008.

SCALA, A., SOLINAS, G., CITTERIO, C.V., KRAMER, L.H., GENCHI, C. Sheep oestrosis (oestrus ovis, Linné, 1761, diptera, oestridae) in Sardania, Italy. Vet. Parasitol. v. 102, p.133$141,2001$.

SCHENKEL, D.M., CAVALCANTE, M.K.M., DAMASCENO, E.S., CAMPOS, A.K., FURLAN, F.H. Surto de Oestrus ovis em ovinos em Mato Grosso. Pesq. Vet. Bras. v.32, p.754-756, 2012. 
SHOORIJEH, J.S., NEGAHBAN, S., TAMADON, A., BEHZADI, M. prevalence and intensity of Oestrus ovis in sheep of Shiraz, southern Iran. Trop. Anim. Health Prod. v.41, p.1259$1262,2009$.

SHOORIJEH, J.S., TAMADON, A., NEGAHBAN, Sh., BEHZADI, M.A. Prevalence of Oestrus ovis in goats of Shiraz, Southern Iran. Vet. arhiv. v.81, n.1, p.43-49, 2011.

SILVA, J. O. A.; CARVALHO-FILHO, F. S.; ESPOSITO, M. C.; REIS, G. A. First record of Chrysomya rufifacies (Macquart) (Diptera, Calliphoridae) from Brazil. Revista Brasileira De Entomologia. v.56, n.1, p.115-118, 2012.

SILVA, S.M.M.S., CASTRO, R.S., COSTA, F.A.L., VASCONCELOS, A.C., BATISTA, M.C.S., RIET-CORREA F., CARVALHO, E.M.S. Conidiobolomycosis in sheep in Brazil. Vet. Pathol. v.44, p.314-319, 2007a.

SILVA S.M.M.S., CASTRO R.S., COSTA F.A.L., VASCONCELOS A.C., BATISTA M.C.S., RIET-CORREA F., CARVALHO E.M.S. Epidemiologia e sinais clínicos da conidiobolomicose em ovinos no Estado do Piauí. Pesq. Vet. Bras. v.27, n.4, p.184-190. 2007b.

SILVEIRA, M.M., PAUlA, D.A.J., SILVA, M.C., PITCHENIN, L.C., CRUZ, R.A.S., COLODEL, E.M., DUTRA, V., NAKAZATO, L. Development and application of polymerase chain reaction test for detection of Conidiobolus lamprauges. Pesq. Vet. Bras. v.33, n.12, p.1448-1452, 2013.

SOUZA, J.M., JUNIOR, A.J.S., NETO, A.F., FUKS, F.B., OLIVEIRA, C.A.C. Rhino facial zygomicosis: case report. Einstein. v.12, n.3, p.347-350, 2014.

SUÁREZ J.L., SCALA A., ROMERO J.A., PAZ-SILVA A., PEDREIRA J., ARIAS M., DIAZ P., MORRONDO P., DIEZ-BANOS P., SANCHEZ-ANDRADE R. Analysis of the humoral immune response to Oestrus ovis in ovine. Vet. Parasitol. v.134, p.153-158, 2005.

TABOSA I.M., RIET-CORREA F., NOBRE V.M., AZEVEDO E.O., REIS-JÚNIOR J.L., MEDEIROS R.M. Outbreaks of pythiosis in two flocks of sheep in northeastern Brazil. Vet. Pathol. v.41, p.412-415, 2004.

TABOURET, G., JACQUIET, P., SCHOLL, P., DORCHIES, P. Oestrus ovis in sheep: relative third-instar populations, risks of infection and parasitic control. Veterinary Research. v.32, p.525-531, 2001.

TABOURET G., LACROUX C., ANDREOLETTI O., BERGEAUD J.P., YACOB H.T., HOSTE H., PRÉVOT F., GRISEZ C., DORCHIES P., JACQUIET P. Cellular and humoral local immune responses in sheep experimentally infected with Oestrus ovis (Diptera:Oestridae). Vet. Res. v.34, p.231-241, 2003. 
TADANO, T., PAIM, N.P., HUEB, M., FONTES, C.J.F. Entomoftoromicose (zigomicose) causada por Conidiobolus coronatus em Mato Grosso (Brasil): relato de caso. Revta. Soc. Bras. Med. Trop. v.38, n.2, p.188-190, 2005.

TREZEGUET, M.A. Prevalencia de enfermedades en 4000 majadas caprinas en los departamentos Atamisqui, Ojo de Agua, Que brachos y Salavina, provincia de Santiago Del Estero, República de Argentina. Vet. Argentina. v.13, p.485-489, 1996.

UBIALI, D.G., CRUZ, R.A.S., DE PAULA, D.A.J., SILVA, M.C., MENDONÇA, E.S., DUTRA, V., NAKAZATO, L., COLODEL, E.M., PESCADOR, C.A. Pathology of nasal infection caused by Conidiobolus lamprauges and Pythium insidiosum in sheep. J. Comp. Path. v.149, p.137-145, 2013.

YILMA, J.M., DORCHIES, PH. Epidemiology of Oestrus ovis in southwest France. Vet. Parasitol. v.40, p.315-323, 1991. 